\title{
Comparing the Performance and Limitations of a Downsized Formula SAE Engine in Normally Aspirated, Supercharged and Turbocharged Modes
}

\author{
William Attard, Harry C. Watson, Steven Konidaris and Mohammad Ali Khan \\ University of Melbourne
}

Copyright $\odot 2006$ SAE International

\begin{abstract} These modes included:
(A) NA with carburetion
(B) NA with port fuel injection (PFI)
(C) Mildly Supercharged (SC) with PFI
(D) Highly Turbocharged (TC) with PFI

This paper compares the performance of a small two cylinder, $430 \mathrm{~cm}^{3}$ engine which has been tested in a variety of normally aspirated (NA) and forced induction modes on 98-RON pump gasoline. These modes are defined by variations in the induction system and associated compression ratio (CR) alterations needed to avoid knock and maximize volumetric efficiency ( $\eta_{\mathrm{VOL}}$ ).

The results have significant relevance in defining the limitations for small downsized spark ignition (SI) engines, with power increases needed via intake boosting to compensate for the reduced swept volume. Performance is compared in the varying modes with comparisons of brake mean effective pressure (BMEP), brake power, $\eta_{\text {VoL }}$, brake specific fuel consumption (BSFC) and brake thermal efficiency $\left(\eta_{\mathrm{TH}}\right)$.

The test engine used in experiments was specifically designed and configured for Formula SAE, SAE's student Formula race-car competition. A downsized twin cylinder in-line arrangement was chosen, which featured double overhead camshafts and four valves per cylinder. Most of the engine components were specially cast or machined from billets.

Experimental results showed BSFC or $\eta_{\mathrm{TH}}$ values in the order of $240 \mathrm{~g} / \mathrm{kWh}$ or $34 \%$ could be achieved. TC BMEP values in the region of 25 bar were also achieved, the highest recorded for small engines on pump gasoline [1]. The engine was installed into successive Melbourne University Racing (MUR) vehicles in 2003 and 2004, where it was very competitive, finishing first in the fuel economy event at the 2004 Australasian competition.

\section{INTRODUCTION}

In recent times, research into SI engine downsizing has grown in popularity $[2,3,4]$ as governments begin to limit carbon dioxide $\left(\mathrm{CO}_{2}\right)$ emissions and consumers strive for cost savings due to rising oil prices. Thus, manufacturers are trying to improve performance and efficiency while meeting legislative pollutant emissions standards. Downsizing, defined as a reduction in the engine swept volume with performance retained by intake boosting, appears to be a major way forward in satisfying consumer and manufacturer requirements.

However, for downsized engines to be comparable to their larger counterparts, the specific output performance must be increased by a ratio equal to the reduction in engine size [3]. This high specific output can only be achieved with the help of increased engine speeds and/or intake boosting. This increases the induced amount of air and fuel, thus enabling the performance of the downsized engine to be improved to match its larger counterpart. Turbocharging seems to be the most acceptable solution to meeting the requirements, with high pressure ratios achievable and well documented improvements in efficiency $[4,5,6,7,8]$.

TC downsized engines also offer other benefits besides obvious efficiency gains. Engine packaging and overall powerplant weight reduction is improved, which further enhances vehicle efficiency and dynamic performance. Smaller engines also offer mass reductions in engine out exhaust emissions, with reduced need for stratified lean burn strategies to improve efficiency. Thus legislative specific emission standards can be met using conventional after treatment methods (three-way catalyst) at stoichiometric operating conditions.

However, disadvantages also exist with smaller downsized engines. The increased specific output places greater strain on the internal components of the engine due to the increased combustion and inertia loading associated with intake boosting and increased engine speeds. This increases the cost and complexity 
as there is a need to redesign internal components using improved materials and manufacturing processes. More elaborate control systems are also needed to prevent component failure. These measures are required to ensure reliability and durability over the engine's life cycle, resulting in increased costs. The higher pressures and temperatures associated with TC engines also increase the occurrence of uncontrolled combustion, mainly knock in the end-gas region, which further deteriorates engine performance and reliability $[6,9]$.

The original intent of this development program was to achieve success in Formula competition by using a far superior engine package when compared to conventional OEM based motorcycle units. However, from the research and development process, results from this small engine operating in a variety of modes has significance in defining the limitations for small downsized gasoline engines. For instance, is the performance limited by engine mechanics, deliverable manifold absolute pressure (MAP) levels, normal or abnormal combustion or a combination of these factors? Results may give some insight to the extent by which engines can be downsized and the specific areas where future research should be directed. This has significant relevance to manufacturers, who continue to strive for swept capacity reductions, while maintaining performance with improved efficiency.

\section{TEST ENGINE}

The test engine used in experiments was specifically designed and developed at the University of Melbourne for use in Formula SAE. The $434 \mathrm{~cm}^{3}$ twin cylinder inline arrangement featured double overhead camshafts and four valves per cylinder, along with a three speed transmission and dry sump lubrication. Further general specifications applicable to all modes are given in Table 1 , with Figure 1 highlighting a sectional view of the engine design.

Table 1: Specifications for the UniMelb 'WATTARD' engine, specifically designed and developed for Formula competition.

\begin{tabular}{|ll|}
\hline BRAND & $\begin{array}{l}\text { UniMelb 'WATTARD' } \\
\text { TYPE }\end{array}$ \\
& $\begin{array}{l}\text { Parallel twin } 4 \text { stroke SI, } \\
\text { Liquid-cooled, } \\
\text { Integral clutch/ transmission }\end{array}$ \\
CAPACITY & $433.8 \mathrm{~cm}^{3}$ \\
BORE X STROKE & $69 \times 58 \mathrm{~mm}$ \\
FIRING ORDER & Unequal $\left(0^{\circ}, 180^{\circ} \mathrm{CA}\right)$ \\
COMPRESSION RATIO & $9-13: 1$ with piston modification \\
COMBUSTION CHAMBER & Pent roof, Central spark plug \\
VALVE ACTUATION & 8-valve DOHC \\
VALVE TIMING & IVO $24^{\circ}$ BTDC \\
& IVC $72^{\circ}$ ABDC \\
& EVO $57^{\circ}$ BBDC \\
LUBRICATION & EVC $9^{\circ}$ ATDC \\
ENGINE MANAGEMENT & Dry sump \\
CLUTCH & Motec M4 EMS \\
TRANSMISSION & Multi wet plate \\
\hline
\end{tabular}

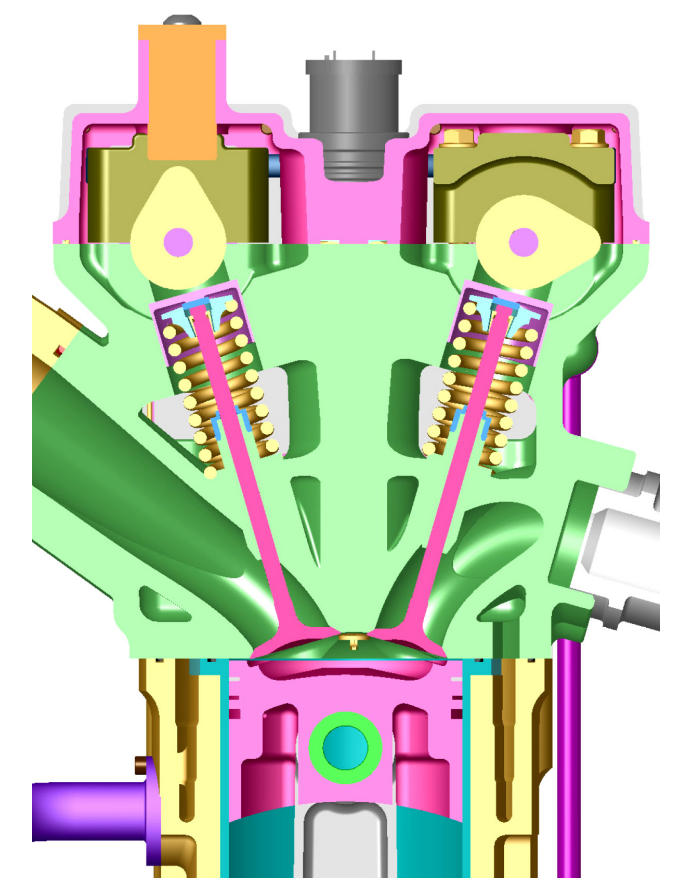

Figure 1: Engine sectional view, highlighting the cylinder head, barrel and reciprocating assembly.

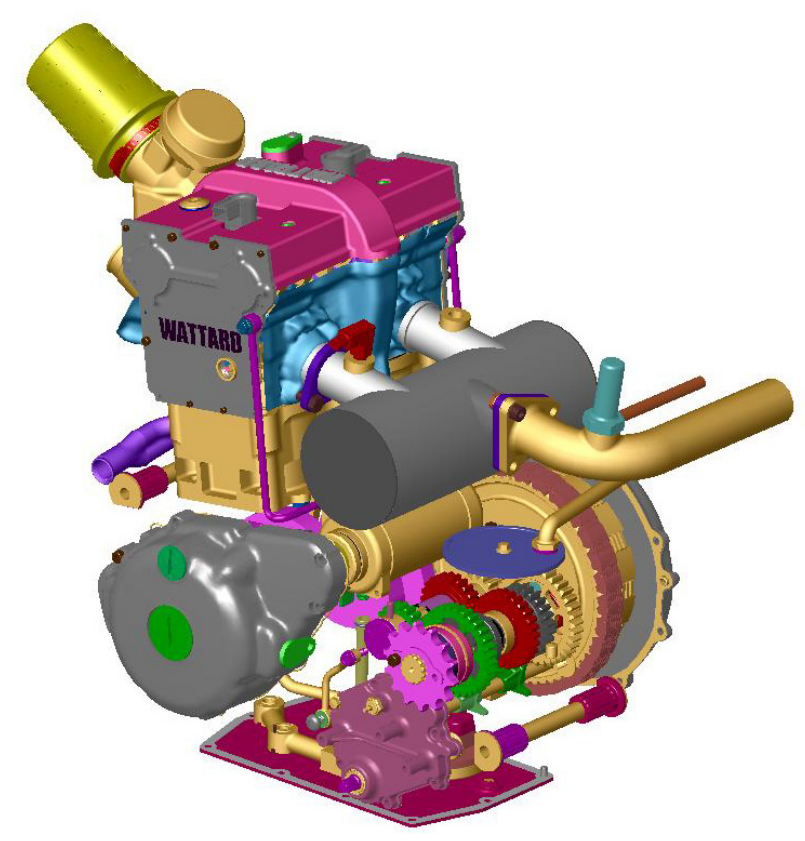

Figure 2: $C A D$ image of the UniMelb 'WATTARD' engine, Mode A - NA with carburetion.

The design brief for the engine featured specific downsizing when compared to typical four cylinder 600 $\mathrm{cm}^{3}$ engines used in the Formula, with regulations dictating maximum capacity at $610 \mathrm{~cm}^{3}$. Downsizing had obvious packaging advantages including large reductions in mass, physical size and centre of gravity (COG) height, which all contributed to improving the dynamic performance of the Formula vehicle $[10,11,12]$. A specifically designed downsized engine also allowed 
the positioning of many major components, including manifolds and the turbocharger to suit Formula applications. Brake power could also improve with the maximum mass flow limited by the mandatory $20 \mathrm{~mm}$ diameter intake restriction. If the restriction could be choked, delivered power would increase due to the reduction in frictional losses associated with the smaller capacity $[11,12,13,14]$.

The clean sheet design approach centered around withstanding the challenges associated with TC engines. Consequently, the capacity and configuration were dictated by turbocharger limits, with the internal components designed to withstand the high specific output. Turbocharging also allowed the maximum mass flow through the restrictor to be maintained over a wide speed range via boost regulation.

During the design phase, little emphasis was placed on emission control as Formula rules did not govern specific emissions. Thus direct injection (DI), exhaust gas recirculation (EGR) and other strategies were dismissed due to their added cost, complexity and associated mass. Intercooling exhibited the potential to decrease knock tendency due to reduced intake charge temperatures. However, maximum delivered air mass flow could not be improved due to the intake restriction. Hence intercooling was dismissed due to the associated large volumes between the engine and compressor and regulated upstream throttle location.

Extensive CFD optimisation was completed due to a shortage of published data and design rules on turbocharging small odd fire gasoline engines. Thus, the manifold design, plenum volumes and valve timing events were optimized using Ricardo's WAVE $®$ for the highly TC mode depicted in Figure 4. Excellent agreement between predicted and actual performance highlighted the success of the TC simulations $[11,12,13,14]$. Thus, the valve timing and exhaust manifold geometry were held constant over all test modes in order to minimize development time. However, provisions were made for CR optimisation to improve performance and efficiency in all test modes, with CAD images depicted in Figures 2 and 3.

The design drew on the University of Melbourne's previous experience in producing small TC engines for a larger engine task, except that Formula SAE engines are significantly smaller and there was much to learn $[7,8]$. The engine research and development program introduced new powerplant concepts to the Formula, which were aimed at improving vehicle performance, as the ultimate goal was to achieve success in competition. New research findings included overcoming the well published oil consumption problems associated with throttled turbocharger compressors $[11,12,13,15]$. Other interesting design features included the novel gasketless cylinder head arrangement used to couple an open deck barrel design to an aluminium alloy cylinder head [16].

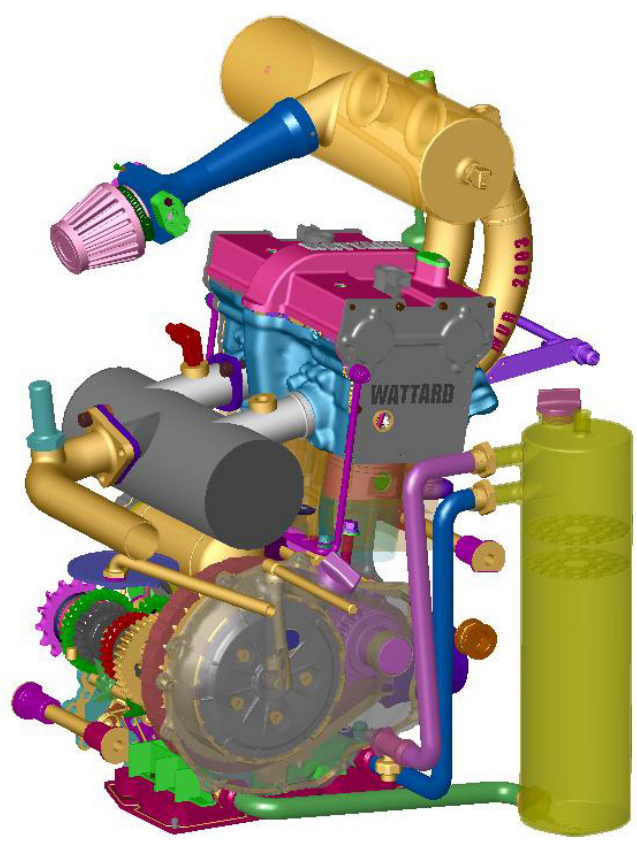

Figure 3: $C A D$ image of the UniMelb 'WATTARD' engine, Mode B and C - NA and externally SC with PFI.
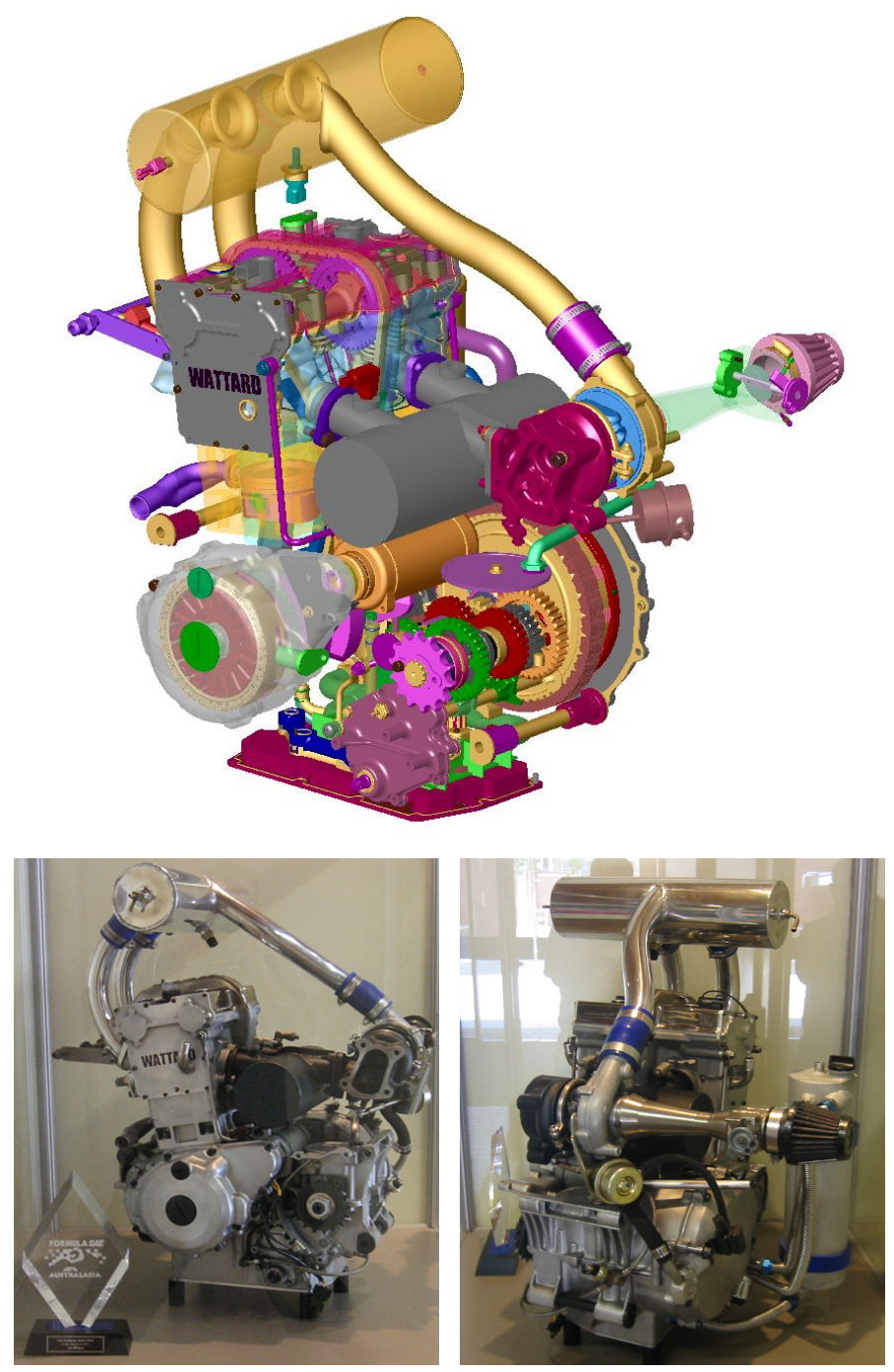

Figure 4: UniMelb 'WATTARD' engine, Mode D - TC with PFI. (upper): $C A D$ image. (lower): Final version together with the fuel economy trophy from the 2004 Australasian competition. 


\section{FUEL PROPERTIES AND DELIVERY SYSTEMS}

Trends in fuel availability at the pump suggest future increases in gasoline quality, as ethanol and other high octane constituents become more widespread. Octane enhancement is vital in improving knock resistance as manufacturers continue to strive for higher CRs to improve efficiency. It was assumed that future downsized small engines would operate on a readily available premium grade of gasoline. Thus all experimentation was completed using a 98-RON pump gasoline labeled Shell Optimax, with specifications given in Table 2. Some fuel testing was completed using an ASTM - CFR single cylinder research engine to confirm its published octane specifications.

Table 2: Specifications for the Shell Optimax premium grade pump gasoline used in all experimental testing.

\begin{tabular}{|l|c|}
\hline \multicolumn{1}{|c|}{ GASOLINE FUEL PROPERTY } & VALUE \\
\hline Research Octane Number (RON) & 98 \\
\hline Density $\left(\mathrm{kg} / \mathrm{m}^{3}\right.$ ) & 760 \\
\hline Molecular mass (kg/kmol) & 110 \\
\hline Lower Heating Value (MJ/kg) & $42.0-44.3$ \\
\hline Stoichiometric AFR (mass basis) & 14.6 \\
\hline Stoichiometric AFR (volume basis) & $60: 1$ \\
\hline Auto Ignition Temperature (K) & $501-744$ \\
\hline Limits of Flammability (F/A) / (F/A) stoic. & $0.75-3.79$ \\
\hline Volatility (ASTM D86) & \\
10\% evaporated (K) & 318 \\
50\% evaporated (K) & 378 \\
90\% evaporated (K) & 428 \\
Final Boiling Point (K) & 469 \\
\hline
\end{tabular}

Experimentation was completed using two different fuel delivery methods involving carburetion and PFI. The use of carburetion was initially chosen as it reduced the complexity during the initial calibration phase of commissioning the prototype engine and testing facility. The carbureted system allowed mixtures to be self controlling after initial jetting due to the mass flow device. This was extremely helpful in troubleshooting other areas as the system was independent of all electronics and sensors and thus focus could be placed on developing the internals of the custom engine. This system was used for NA running due to the carburetor limitations involving boost and implementing the mandatory intake restriction for Formula SAE operation. Once engine reliability was ensured, the sequential PFI system was fitted, with specifications for both systems given in Table 3.
Table 3: Fuel delivery specifications for the carburetted and PFI systems used in experimental testing.

\begin{tabular}{|c|c|c|}
\cline { 2 - 3 } \multicolumn{1}{c|}{} & \multicolumn{2}{c|}{ FUEL DELIVERY } \\
\cline { 2 - 3 } \multicolumn{1}{c|}{ Type } & Carburetion & PFI \\
\hline Brand & $\begin{array}{c}\text { Downdraught, } \\
\text { constant vacuum }\end{array}$ & $\begin{array}{c}\text { Sequential Injection, } \\
\text { 4 orifice nozzle }\end{array}$ \\
\hline Part No. & BDSR36 & Bosch \\
\hline Quantity & $\begin{array}{c}1 \text { carburetor / } \\
\text { cylinder }\end{array}$ & $\begin{array}{c}1 \text { injector } / \\
\text { cylinder }\end{array}$ \\
\hline Fuel Pressure & Gravity fed & $\begin{array}{c}500 \text { kPa absolute } \\
\text { across injector, } \\
\text { MAP reference }\end{array}$ \\
\hline
\end{tabular}

\section{INDUCTION SYSTEMS}

The use of alternative fuel supply systems and intake conditions necessitated differing intake manifolds between the test modes. For all PFI systems, the intake plenum volume, intake runner length and intake restriction were fixed at constant values, with the manifold layout changing to accommodate TC running. However, it was impractical to use carburetion on the single restrictor intake manifold, resulting in the implementation of an OEM system without a restrictor. Exhaust manifold geometry was held constant over all modes with exhaust duct changes allowing turbocharger implementation. Further details are given in Table 4, with associated exploded views of the intake and exhaust manifold designs shown in Appendix A and B.

Table 4: Specifications defining intake and exhaust manifold geometry for the varying modes and associated fuel delivery systems.

\begin{tabular}{|c|c|c|c|}
\cline { 2 - 4 } \multicolumn{1}{c|}{} & \multicolumn{3}{c|}{ MODE } \\
\cline { 2 - 4 } \multicolumn{1}{c|}{} & (A) & (B)\& (C) & (D) \\
\hline Fuel Delivery & Carburetion & \multicolumn{2}{c|}{ PFI } \\
\hline $\begin{array}{c}\text { Intake Manifold } \\
\text { Design (Appendix A) }\end{array}$ & $\begin{array}{c}\text { SHEET } \\
12.2\end{array}$ & $\begin{array}{c}\text { SHEET } \\
12.3\end{array}$ & $\begin{array}{c}\text { SHEET } \\
12.4\end{array}$ \\
\hline $\begin{array}{c}\text { 20mm Intake } \\
\text { Restriction }\end{array}$ & NO & YES & YES \\
\hline $\begin{array}{c}\text { Intake Plenum } \\
\text { Volume (L) }\end{array}$ & N/A & 4.5 & 4.5 \\
\hline $\begin{array}{c}\text { Primary Intake } \\
\text { Length (mm) }\end{array}$ & 200 & 350 & 350 \\
\hline $\begin{array}{c}\text { Exhaust Manifold } \\
\text { Design (Appendix B) }\end{array}$ & $\begin{array}{c}\text { SHEET } \\
11.1\end{array}$ & $\begin{array}{c}\text { SHEET } \\
11.1\end{array}$ & $\begin{array}{c}\text { SHEET } \\
11.3\end{array}$ \\
\hline
\end{tabular}


Table 5 highlights the maximum desired intake conditions for the varying test modes. Maximum operating conditions at wide open throttle (WOT) for the NA modes were limited to atmospheric conditions, with the aid of intake resonant tuning to improve air consumption.

The two boosted modes varied significantly in their airflow delivery method. Mode C involved mildly supercharging the engine using a positive displacement Roots type supercharger. Coupling of this system to the engine was trivial, achieved via installing a flexible duct from the outlet of the externally driven supercharger to the intake assembly. MAP was controlled by varying the throttle position as the throttle body/restrictor system was located between the supercharger and the intake manifold. Original reasoning behind this development involved establishing parametric constraints to find the engine's limitations under mild boost with no exhaust influence. A maximum boost level of half an atmosphere was desired to gauge knock severity at low engine speeds and to ensure engine reliability at the higher CRs. The SC data provided valuable insight into the engine modifications needed to sustain high pressure ratio turbocharging.

Maximum pressure ratios in the TC mode at WOT were dictated by intake restrictor choking limits and corresponding engine speeds. The objective was to maintain a choked restricted inlet at the lowest possible engine speed to broaden and increase the delivered power, which improved vehicle drivability $[10,11,12,14]$. Thus, maximum boost levels in the manifold were dictated by what the turbocharger could deliver and were expected to be greater than 1.5 atmospheres, needed to produce sonic flow at mid range speeds. Boost pressure needed to be reduced as engine speed increased to maintain sonic conditions and avoid excessive exhaust back pressure. This was achieved using the turbocharger internal wastegate, which bypassed exhaust flow past the turbine. A diaphragm operated actuator with reference to MAP controlled wastegate movement, with the reference signal manipulated via a bleed valve controlled through the engine management system (EMS). This allowed boost pressure to be electronically controlled at user defined functions of engine speed and throttle position.

Table 5: Defining the desired maximum operating conditions for all test modes.

\begin{tabular}{|l|c|}
\hline \multicolumn{1}{|c|}{ MODE } & $\begin{array}{c}\text { MAX MAP (kPa) } \\
\text { AT WOT }\end{array}$ \\
\hline (A) NA - Carburetion & 100 \\
\hline (B) NA - PFI & 100 \\
\hline (C) SC - PFI & 150 \\
\hline (D) TC - PFI & $\begin{array}{c}\text { Maximum achievable } \\
\text { (restrictor limited) }\end{array}$ \\
\hline
\end{tabular}

\section{EXPERIMENTAL SETUP}

A two year engine testing program commenced after initial engine commissioning. This involved static steady state dynamometer testing coupled with transient testing with the installation of the engine into two successive Formula SAE vehicles to evaluate its performance and reliability. Dynamometer testing involved the commissioning of a stationary engine test cell facility, with the schematic set-up shown in Figure 5.

A MOTEC M4 EMS was used to control the ignition settings for all modes, also controlling fuel delivery rates for the PFI system. This allowed the manipulation of fuel injector pulse width and spark timing at user defined mapping points via a personal computer (PC) connected to the EMS via an RS232 link. Mapping sites were functions of MAP versus speed, generally varying in 500 $\mathrm{rev} / \mathrm{min}$ increments, ranging from 2000 to $11000 \mathrm{rev} / \mathrm{min}$. MAP sites were arranged in $10 \mathrm{kPa}$ increments, starting from $20 \mathrm{kPa}$ absolute to the maximum MAP condition reached at WOT, which varied depending on the test mode.

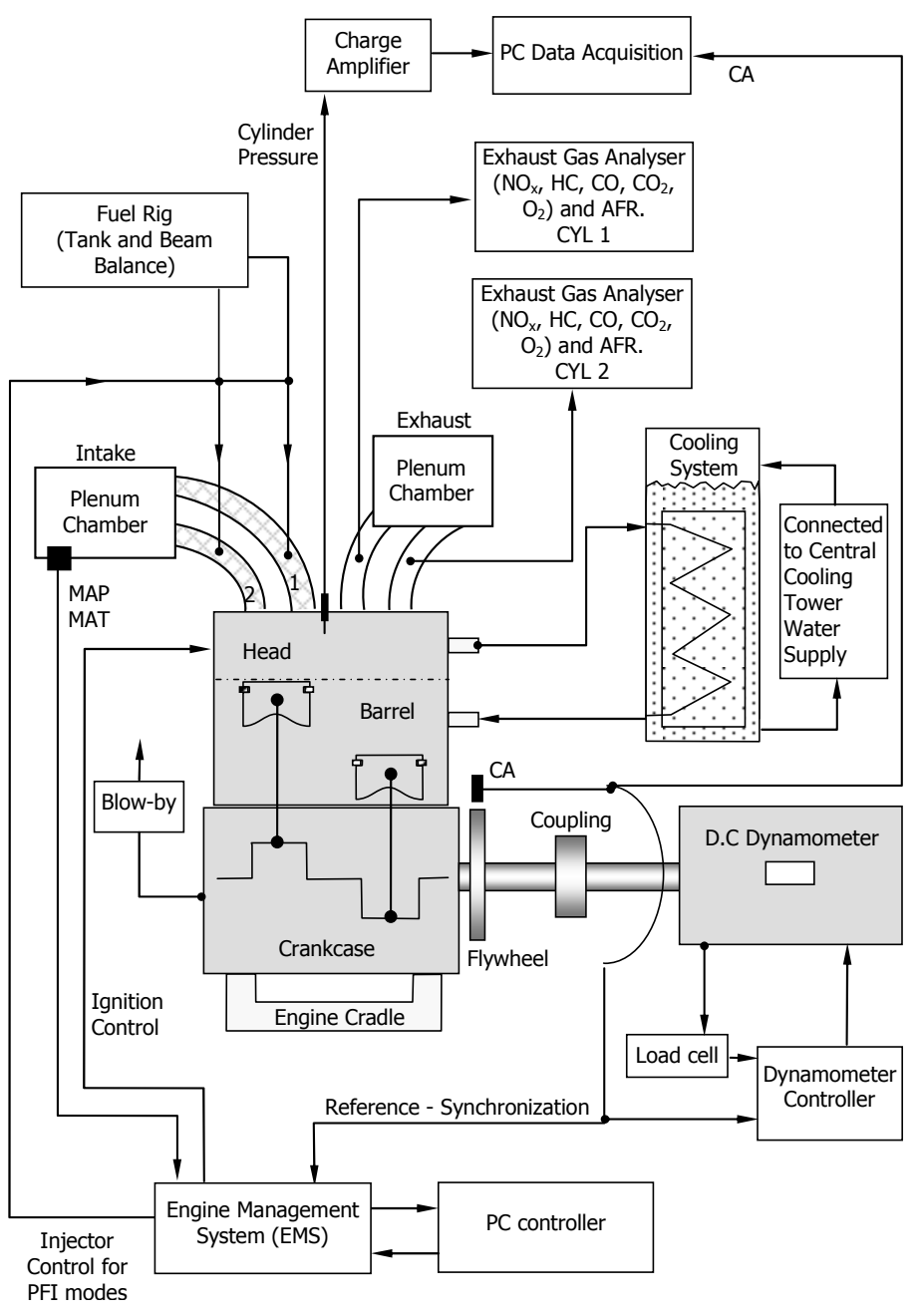

Figure 5: Experimental set-up illustrating the basic schematic layout of the engine, including controllers, sensors and data acquisition systems. 
Having a common fuel consumption measurement system for both carburetion and PFI fuel systems was seen as advantageous for direct back to back comparison. This was achieved gravimetrically using a beam balance mechanism to cancel out the high tank mass via a counterbalance weight. This allowed small changes in mass due to net fuel loss to be detected and measured over time. A schematic of the system is shown in Figure 6 . For the PFI system, injector calibration at duty cycle intervals also allowed fuel flow rates to be measured independently of the beam balance and thus results could be cross-checked for accuracy. This was possible by ensuring the pressure across the injector remained constant for varying MAP conditions and thus achieved with the implementation of a rising rate pressure regulator. This modulated fuel supply pressure via a MAP feedback signal from the intake manifold. Fuel pressure across the injector was set at $500 \mathrm{kPa}$ absolute for all PFI engine operation.

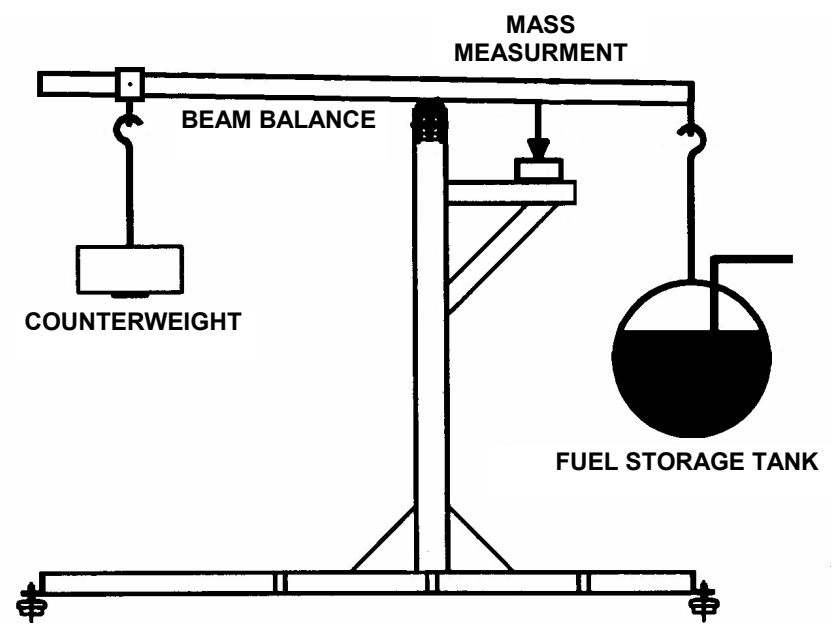

Figure 6: Schematic layout of the calibrated gasoline mass measurement system.

The mass flow rate of air was not measured directly, but instead computed using the known fuel mass flow rate and air/fuel ratio (AFR). The overall AFR was measured using two methods:

$>$ Directly using a Bosch LSU 5-wire wide band heated exhaust gas oxygen (HEGO) sensor positioned downstream of the exhaust manifold

$>$ Via calculation from the known individual cylinder exhaust products from the NDIR fivegas exhaust gas analyzer, positioned in each cylinder's exhaust header.

In this way, the measurements could be cross-checked for accuracy and an average lambda value computed.

A water cooled, eddy current type Heenan and Froude Dynamatic MK-1 brake dynamometer was used to absorb load. Rated at absorbing $110 \mathrm{~kW}$ between 2400 and $6000 \mathrm{rev} / \mathrm{min}$, it features a water-cooled field stator and rotor to minimize thermal growth in the assembly due to the heat generated via the torque absorption. An
OZY-DYN type MISD109-01 controller allowed steady state engine testing at user defined dynamometer speeds. Quarterly load cell calibration was performed by applying known masses to a beam at a fixed distance from the dynamometer pivot axis, thus ensuring results were accurate and repeatable. Relative humidity, calculated via wet and dry bulb temperatures together with barometric pressure allowed raw brake data to be corrected to ISO-3046 international standards for internal combustion engine performance [17].

As a result of the engine design, featuring an integral clutch and constant mesh gearbox within the crankcase, coupling of the engine crankshaft directly to the dynamometer proved unfeasible. Thus the dynamometer was coupled to the gearbox output shaft, with testing completed in top gear to ensure minimal differential speeds between the crankshaft and the dynamometer. Thus all brake data presented in this paper corresponds to the performance at the gearbox output shaft and not at the crankshaft. Performance at the crankshaft is expected to be marginally higher, due to the reduction in frictional losses associated with driving the transmission components.

Blow-by measurement was made possible by sealing the crankcase and venting all blow-by gas through a calibrated rotameter. This was especially useful during engine run-in, as the piston ring seal could be gauged before applying heavy load, thus ensuring engine reliability. Development time and failure consequences reduced by detecting sudden fluctuations in blow-by flow as a result of failed piston or piston ring components, facilitating rapid engine shutdown.

It must also be noted that all experimental data were taken at an engine operating temperature varying between $85-90^{\circ} \mathrm{C}$ at a cooling system pressure of 200 $\mathrm{kPa}$ absolute. This was controlled electronically through the EMS via an electric heater enabling pre warm-up prior to testing.

\section{EXPERIMENTAL PROCEDURE}

The strategy employed for testing was to standardise all settings except the variable being tested. These standard settings included the exhaust manifold, valve motion properties and the employed tuning strategy. The variables and associated limitations are now listed.

$>$ Induction system including the associated components required for operation with more detail given in the exploded views of Appendix A. It is noted that the PFI and carburetion modes differed in intake manifold design as previously defined in Table 4.

> Compression ratio variations ranging from 913:1, made possible through piston crown alterations to a set of custom forged pistons. 
Testing for each mode commenced at the highest CR which was limited to $13: 1$. This was the highest achievable with a flat top piston in the pent roof combustion chamber and was expected to be close to optimum for the NA modes [11]. The decision to use a flat top piston was based on manufacturability, with simple machining modifications allowing reductions in CR.

Engine calibration was performed in accordance with the tuning strategy, defined in Table 6 . If knock control could not be achieved through the EMS using tuning strategies, the CR would be decreased in accordance with the knock severity and testing would be continued to find the limits of operation. The knock (KL) and damage limit (DL), previously published by Rothe [18], were used to determine if $C R$ reductions were needed to ensure engine reliability, with the knock amplitude (KA) defined as the zero to peak pressure of the high pass filtered cylinder pressure.

$$
\begin{aligned}
& >\mathrm{KL} \quad 1 \% \text { cycles with } \mathrm{KA}>4 \text { bar } \\
& >\mathrm{DL} \quad 1 \% \text { cycles with } \mathrm{KA}>20 \text { bar }
\end{aligned}
$$

\section{TUNING STRATEGY}

The ignition tuning strategy involved finding the minimum spark advance for maximum brake torque (MBT-ST) or in the case when ignition timing was knock limited, the knock limited spark timing (KL-ST). The first stage of knock control would rely on traditional methods involving varying degrees of spark retard and/or fuel enrichment [5], albeit with the penalty of increased fuel consumption.

The lambda tuning strategy varied depending on the load condition, with lean and stoichiometric mixtures targeted at light and medium loads to improve efficiency and reduce fuel consumption. Richer mixtures were used at heavier load conditions associated with brake performance. This improved brake output and provided component protection due to the reduced combustion temperatures which further enhanced engine reliability.

Fuel injection timing was varied to achieve maximum brake torque (MBT - injection timing), using hydrocarbon $(\mathrm{HC})$ emissions as an indicator of mixing and $\mathrm{CO}_{2}$ as an indicator of combustion efficiency. For assessing AFR and exhaust emissions, the exhaust gas composition was measured in each cylinder's header, using two NDIR five-gas exhaust gas analysers.

The employed tuning strategy had significant relevance to Formula SAE applications, with one of the five dynamic events featuring fuel economy performance. This allowed the engine to conserve fuel when the driver required little power, with significant power increases upon driver demand. Details of the tuning strategy are given in Table 6.
Table 6: Engine tuning strategy applied to all modes over the varying operating conditions.

\begin{tabular}{|c|c|c|c|}
\cline { 2 - 4 } \multicolumn{1}{c|}{} & \multicolumn{3}{c|}{ LOAD CONDITION } \\
\cline { 2 - 4 } \multicolumn{1}{c|}{} & Light & Medium & Heavy \\
\hline $\begin{array}{c}\text { Corresponding } \\
\text { BMEP (kPa) }\end{array}$ & $<300$ & $300-600$ & $>600$ \\
\hline $\begin{array}{c}\text { Corresponding } \\
\text { MAP estimate (kPa) }\end{array}$ & $<60$ & $70-80$ & $>80$ \\
\hline Targeted $\lambda$ & $1.1-1.2$ & 1 & 0.9 \\
\hline Spark Timing & MBT & MBT & MBT or KL \\
\hline $\begin{array}{c}\text { PFI Injection } \\
\text { Timing }\end{array}$ & MBT & MBT & MBT \\
\hline
\end{tabular}

\section{PERFORMANCE LIMITATIONS}

Figure 7 displays the knock and airflow limitations as functions of engine speed, MAP and CR, found from experimental testing. The cross hatched areas indicate domains where engine operation was $\mathrm{KL}$ but could be controlled via tuning strategies previously defined to avoid the DL. The shaded areas in plots indicate where engine operation was not possible due to airflow limitations or heavy knock exceeding the DL. Airflow limitations were only associated with the boosted modes, where compressor delivered airflow was insufficient to meet the operating requirements or the intake restriction limited airflow.

The performance limit (PL), highlighted by the dashed line corresponds to each modes WOT condition. It must be noted that the MAP and thus the PL line varied between modes due to varying operating conditions, previously defined in Table 4. Thus for each mode, cross plots of engine speed versus MAP and CR versus engine speed all share a common PL line in dimensional space.

Plots in Figure 7 have been constructed from multi-CR experimental data points, gathered by incrementally varying the $C R$ to values dictated by the knock severity. These CR values included 9.6, 10, 11, and 13. Resulting piston crown and combustion chamber shapes associated for each $\mathrm{CR}$ are displayed in Appendix C. It should be noted that the positioning and number of piston rings varied to accommodate piston crown changes, blow-by severity and heat transfer requirements. However, a minimum top land thickness of $4 \mathrm{~mm}$ was maintained to ensure piston reliability and longevity.

It must be noted that the carburetion limits of mode $A$ are not shown in Figure 7 as they were not reached. This was partly due to the limitation on the maximum achievable CR, coupled with the richer mixture 
properties at WOT. These mixtures were richer than those defined in the tuning strategy, however, accurate control was difficult to achieve due to the carbureted system. Furthermore, the carbureted system also featured differing intake system geometry when compared to the PFI systems, with shorter intake runners. Thus peak BMEP values occurred at higher engine speeds when compared to the PFI systems, where knock is less susceptible $[18,19]$.

(B) NA - PFI
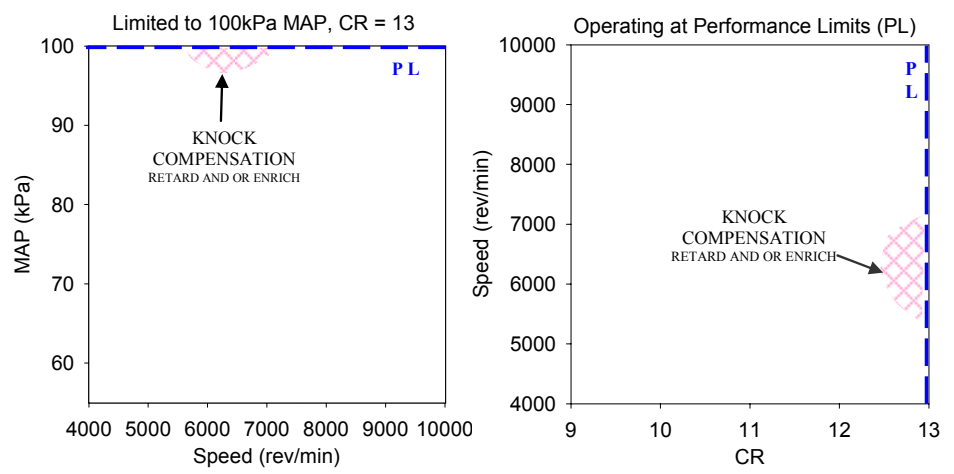

(C) SC - PFI
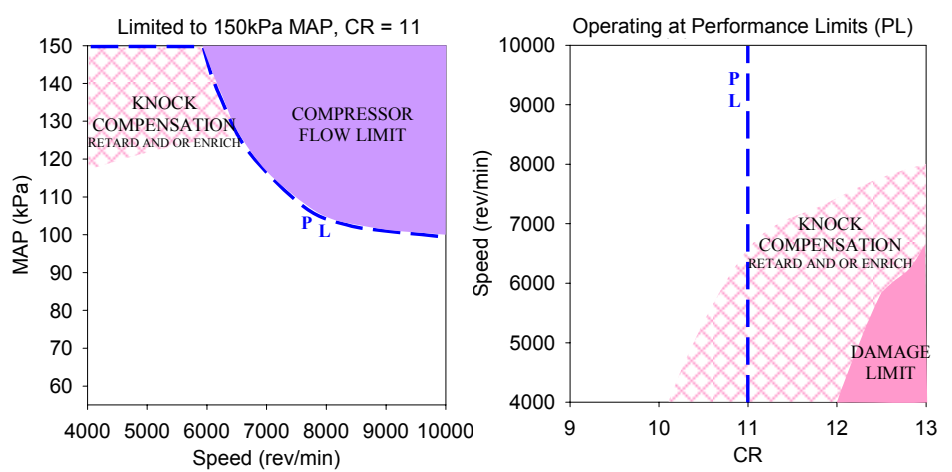

(D) TC - PFI
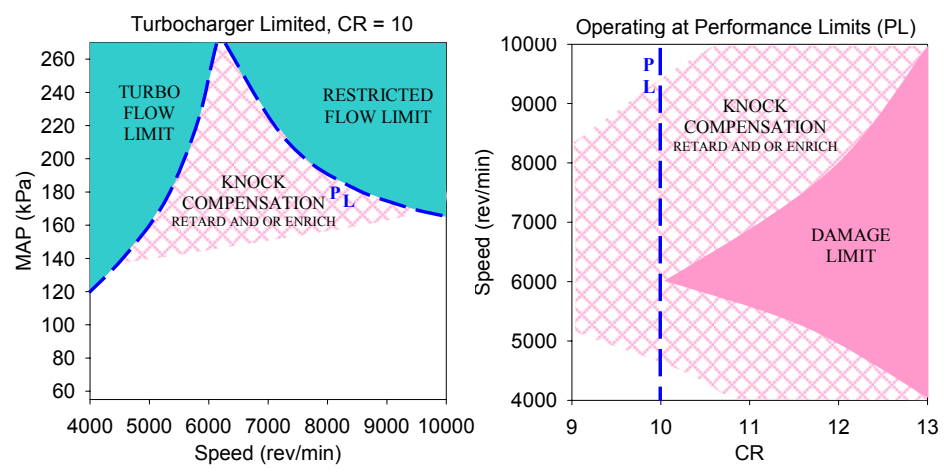

Figure 7: Knock and airflow limitations versus MAP, engine speed and CR for modes B (NA - PFI), C (SC - PFI) and D (TC - PFI). Cross hatched areas indicate operation with spark retard and/or fuel enrichment to compensate for knock. Shaded areas indicate non operation due to knock levels above the $\mathrm{DL}$ or limited airflow. PL is the performance limit line defined at WOT.
Trends from Figure 7 also confirm that for a given CR and MAP condition, knock is less prone at higher speeds. This is a consequence of the increased flame speeds within the combustion chamber, which result in the unburnt mass in the end-gas region being consumed more quickly. This decreases the likelihood of knock due to the reduced end-gas residence time within the combustion chamber.

It is also interesting to note that spark retard and/or fuel enrichment can be used as a method of knock control for up to 1-2 CR points depending on the knock severity. This can be a useful tool during boosted engine development, as it allows the calibrator some margin to avoid the DL without having to reduce the CR.

With spark retard and/or enrichment strategies together with $\mathrm{CR}$ reductions being the only forms of knock control used throughout experimentation, the data gathered must be put into context before any conclusions can be drawn. It is noted that further reductions in knock are expected with the implementation of various other strategies thus affecting the optimum CR for each mode. These strategies could include DI, EGR, intake charge cooling (intercooling and/or evaporative), combustion enhancement through chamber design and increases in fuel octane number $[1,2,5,9,20,21]$. The implementation of $\mathrm{DI}$ alone has documented improvements of one compression ratio point [1].

Table 7 shows the estimated optimum CR for each mode, determined from the experimental data presented in the cross plots of Figure 7 . Some safety margin was assumed in the estimation to ensure the $\mathrm{DL}$ is avoided. The estimated optimum CR is compared to the experimental test $\mathrm{CR}$, which was determined by analysing pressure cycle data during engine development.

Table 7: Estimated optimal $\mathrm{CR}$ and the experimental test $\mathrm{CR}$ which was closest to the estimated optimal.

\begin{tabular}{|l|c|c|}
\hline \multicolumn{1}{|c|}{ MODE } & $\begin{array}{c}\text { ESTIMATED } \\
\text { OPTIMUM CR }\end{array}$ & TEST CR \\
\hline A (NA - Carburetion) & 13.5 & 13 (limited) \\
\hline B (NA - PFI) & 13 & 13 (limited) \\
\hline C (Mildly SC - PFI) & 11.5 & 11 \\
\hline D (Highly TC - PFI) & 9.5 & 10 \\
\hline
\end{tabular}

\section{KNOCK}

Figure 8 displays the cylinder pressure for a heavy knocking cycle, with the knock amplitude well above the DL previously defined. Running at this limit has well published associated problems, ranging from component surface erosion to failure depending on the knock location and severity. The literature together with 
experiments has shown common damaged components to include pistons, cylinder bores and liners, piston rings, big end bearings and spark plugs which lead to significant and costly engine damage $[9,21]$. Cylinder head gaskets are also prone to failure, but were not experienced due to the engine's gasketless design [16].
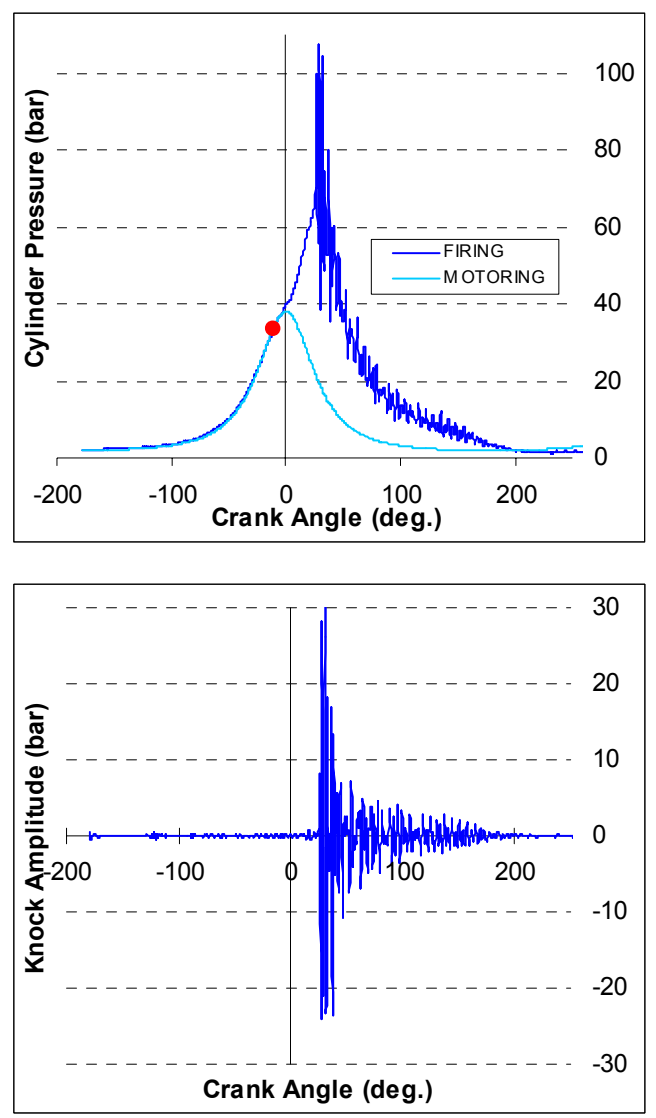

Figure 8: A recorded heavy knocking cylinder pressure cycle well above the DL. Mode D (PFI - TC), $7000 \mathrm{rev} / \mathrm{min}, 11: 1$ CR, 220 kPa MAP.

Engine development initially commenced with no form of knock detection due to a lack of expertise involving knock sensor implementation and difficulty in physically locating a cylinder pressure transducer in the pent roof combustion chamber. As an alternative, the engine operator was relied upon to audibly discern the knock severity. This proved to be troublesome as depicted in Figure 9, with several top land piston failures occurring early in development. With the engine design featuring a gasketless interface, knock above the DL would quickly result in piston failure due to the absence of gasket weakspot [16].

It is also interesting to note that all piston land failures occurred on the intake side, with negligible difference in piston land structural integrity between the inlet and exhaust sides. This is contrary to what was anticipated, with published results indicating higher exhaust side surface temperatures in comparison to the intake side $[9,22]$. However, with pent roof combustion chambers, knock severity is highest on the intake side due to the knock onset location's dependence on the flame front. As the flame front travels over the cooler surfaces of the intake valves, the flame speed significantly reduces. Hence, surface temperature distribution within the combustion chamber plays a secondary role in knock location and severity [18].

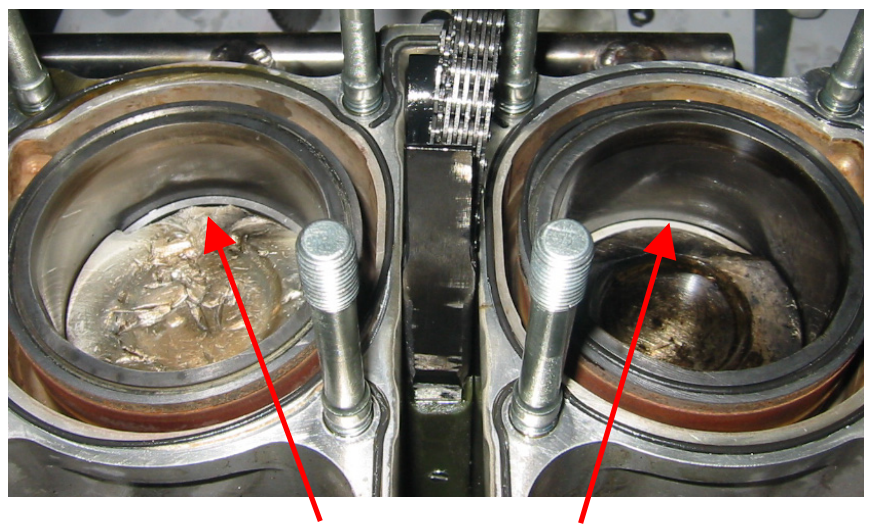

INLET SIDE PISTON LAND FAILURE

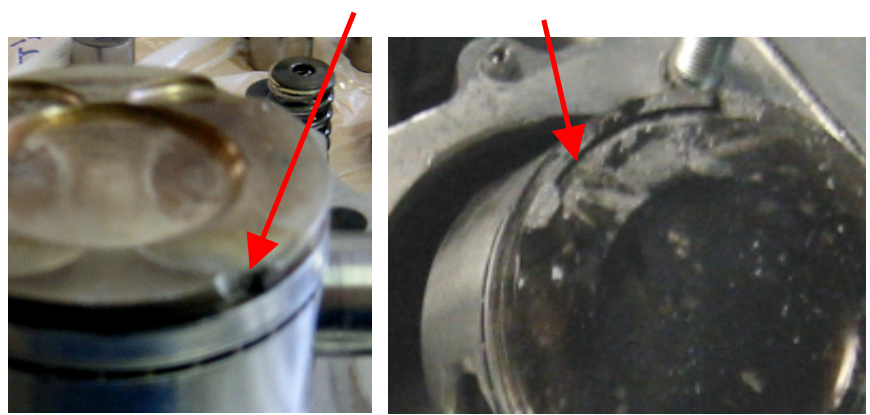

Figure 9: Adverse effects of heavy knock in the end-gas region above the DL. (upper): Simultaneous inlet side piston land failure in both cylinders. (lower): Further inlet side failures after increased piston oil cooling, directed towards the piston intake underside.

The relevance of this recently published finding is further enhanced by the piston development, which was undertaken to reduce knock intensity during turbocharger implementation at higher CRs. The first inlet side top land failure was originally thought to have been caused by high intake side surface temperatures as the piston received underside oil cooling via a single jet directed towards the exhaust side. However, inlet side top land failure continued to occur after the implementation of a jet directed towards the inlet side. This jet varied in orifice size, originally having the same flow capacity as the exhaust side with a $0.45 \mathrm{~mm}$ diameter orifice. Oil flow was later increased four fold, but yielded no change in knock location or piston failure severity at the elevated CR. $\mathrm{CR}$ reduction was eventually needed to reduce knock intensity to acceptable limits.

Repositioning the spark plug towards the inlet side may be an option to prevent the flame speed discrepancies associated with the cooler intake side surface 
temperatures. Consequently, the traveling flame front would engulf the intake and exhaust side end-gas region simultaneously, thus reducing the likelihood of end-gas knock. In itself, the simultaneous arrival of the flame in the end-gas around the piston increases efficiency and power, as the reduced burn time allows further increases in $\mathrm{CR}$, which has additional benefits.

However, the positioning of the spark plug is largely dictated by space limitations due to the compact nature of the pent roof combustion chamber. As a result of the larger intake valves, the spark plug is normally offset towards the exhaust side in conventional cylinder head design. Intake boosting would allow for the use of smaller intake valves and thus the repositioning of the spark plug closer to the bore centre, or even biased towards the intake side.

After several piston failures, a Kistler 601-B1 cylinder pressure transducer was installed according to Kistler remote mounting instructions. However, non-flush mounting caused excessive resonance within the connecting passage and clearance chamber, producing high noise signals. This was overcome by flush mounting and coating the transducer with high temperature RTV silicon to avoid thermal shock [11,23]. This significantly reduced development time, as any form of knock could be detected and avoided before piston land failure. It is also interesting to note that the audible noise associated with the heavy knocking condition was closer to a high frequency crackle at the elevated engine speeds, quite different to knock in conventional engines.

\section{EXPERIMENTAL RESULTS: VARYING MAP}

Contour plots are shown with the purpose of establishing trends for brake performance and efficiency across the range of test modes. Throughout the two year experimental period, small variations in prescribed operating conditions meant that the raw data needed to be interpolated to a rectangular grid using a smoothing algorithm, enabling contour plots to be generated. This was achieved by applying a Loess smoothing algorithm with tricube weighting and polynomial regression to the 250 experimental data points. Contours are also extrapolated past the airflow limitations so the reader can deduce expected results if the limitations were removed.

All contour plot data presented is expressed in the engine speed versus MAP domain, at the experimental test CR which was closest to the previously estimated optimum, defined in Table 7 for all modes. Also, as previously described, the shaded areas in plots indicate where engine operation was not possible due to airflow limitations associated with insufficient compressor airflow or the restricted inlet. The PL line corresponds to the WOT condition.
Figure 10 displays BMEP contours for the varying modes. Increases in BMEP are shown to be directly proportional to increases in MAP for all speeds, as expected. This is primarily due to engine air consumption increases, with BMEP dependent on airflow, combustion and frictional losses. For all PFI systems, for a given MAP unlimited by airflow, peak BMEP occurs in the $7000 \mathrm{rev} / \mathrm{min}$ region, which corresponds to the tuned intake speed. For the carbureted system, peak BMEP occurs at a higher speed due to the shorter inlet tracts. Above the tuned intake speed, BMEP falls quickly as the induced airflow and mechanical efficiency decreases due to the increased frictional losses associated with the higher speeds.
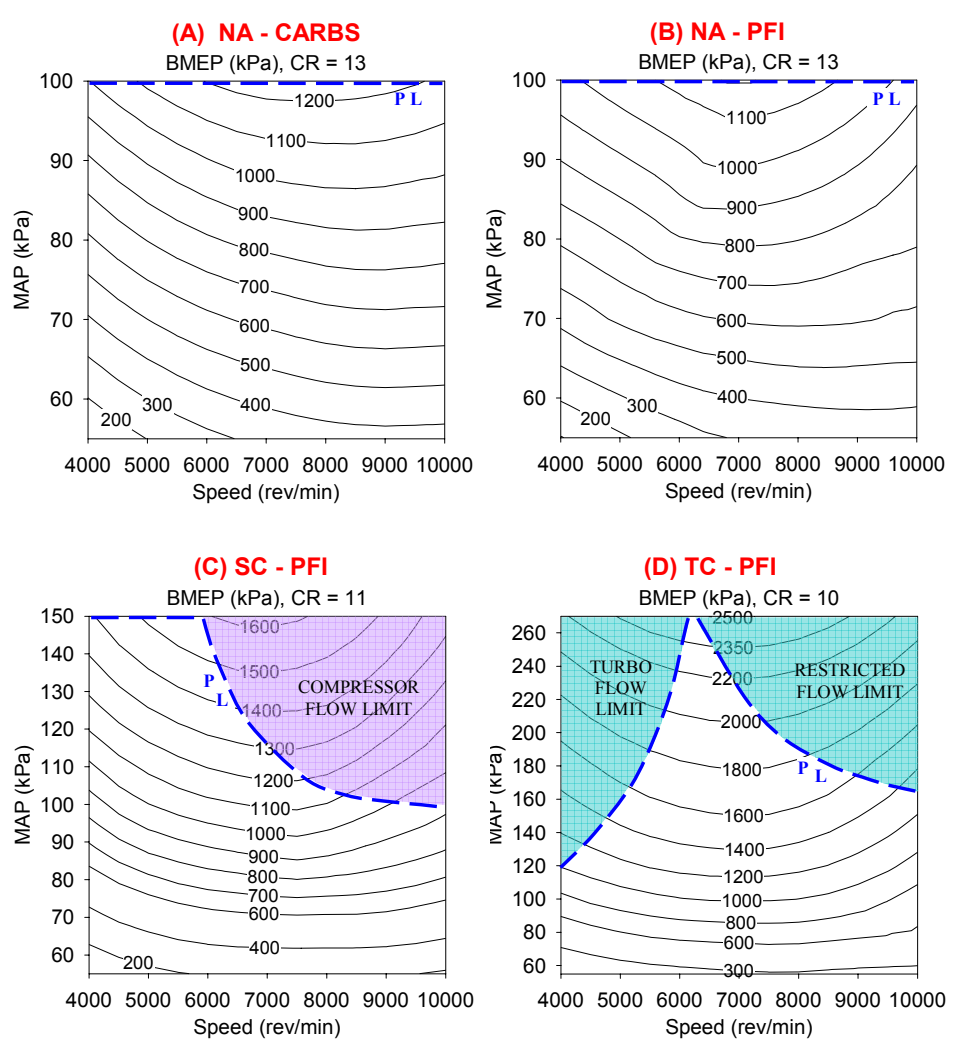

Figure 10: BMEP trends at the test CR closest to optimal, varied MAP and speed conditions. Shaded areas indicate airflow limited regions. $P L$ is the performance limit line defined at WOT.

\section{BRAKE POWER}

From Figure 11, it is clearly evident that for all fixed speeds, brake power increases as a direct result of increasing MAP. This is expected as brake power is directly proportional to BMEP and engine speed. 
For all test modes, brake power increases are evident for increases in speed at a fixed MAP. However, at the higher speeds, the rate of power increase begins to level as reductions in BMEP are offset by increasing engine speeds. In the boosted modes, it is interesting to note that near constant power contours are evident at the PL line, where maximum airflow is maintained over a varying speed range due to the airflow limitations. This indicates that brake power is heavily dependent on airflow, as expected.

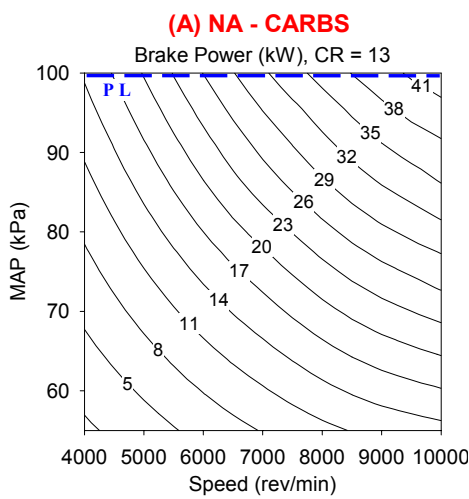

(C) SC - PFI

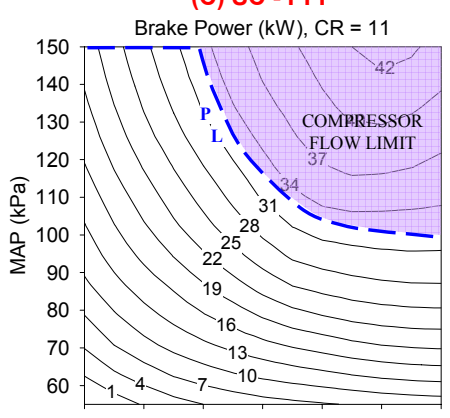

40005000600070008000900010000 Speed (rev/min)

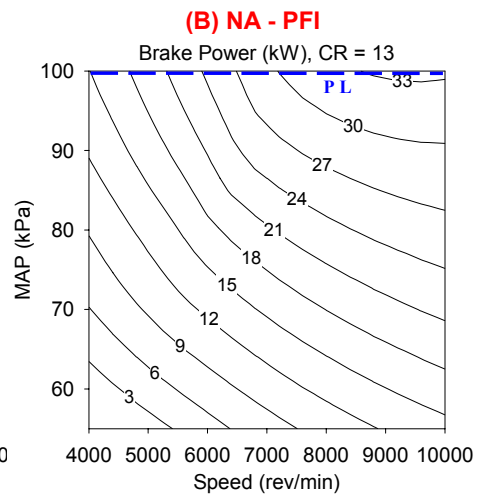

(D) TC - PFI

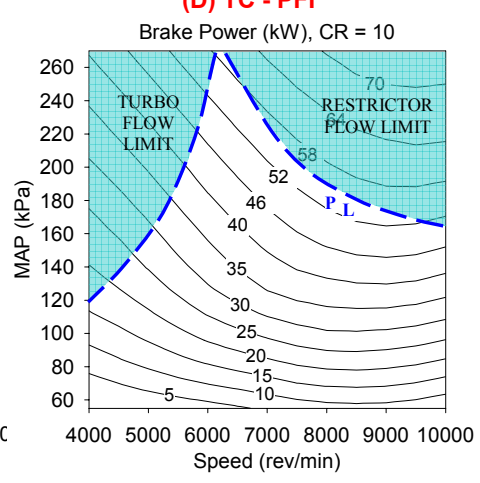

Figure 11: Brake power trends at the test CR closest to optimal, varied MAP and speed conditions. Shaded areas indicate airflow limited regions. PL is the performance limit line defined at WOT.

\section{SPARK TIMING}

MBT-ST is usually limited by the onset of knock at high MAP and/or high CR values and thus the spark timing is knock limited (KL-ST). Trends from Figure 12 show that as the speed increases, for all conditions, the spark must be advanced to maintain MBT-ST since the combustion burn duration in crank angle (CA) degrees increases. Reductions in spark advance values as the MAP increases are results of knock compensation (KL$\mathrm{ST}$ ) and/or decreases in burn duration. Decreases in burn duration are caused by increased flame speeds as the charge density within the cylinder increases as a result of the reduced residual gas content.
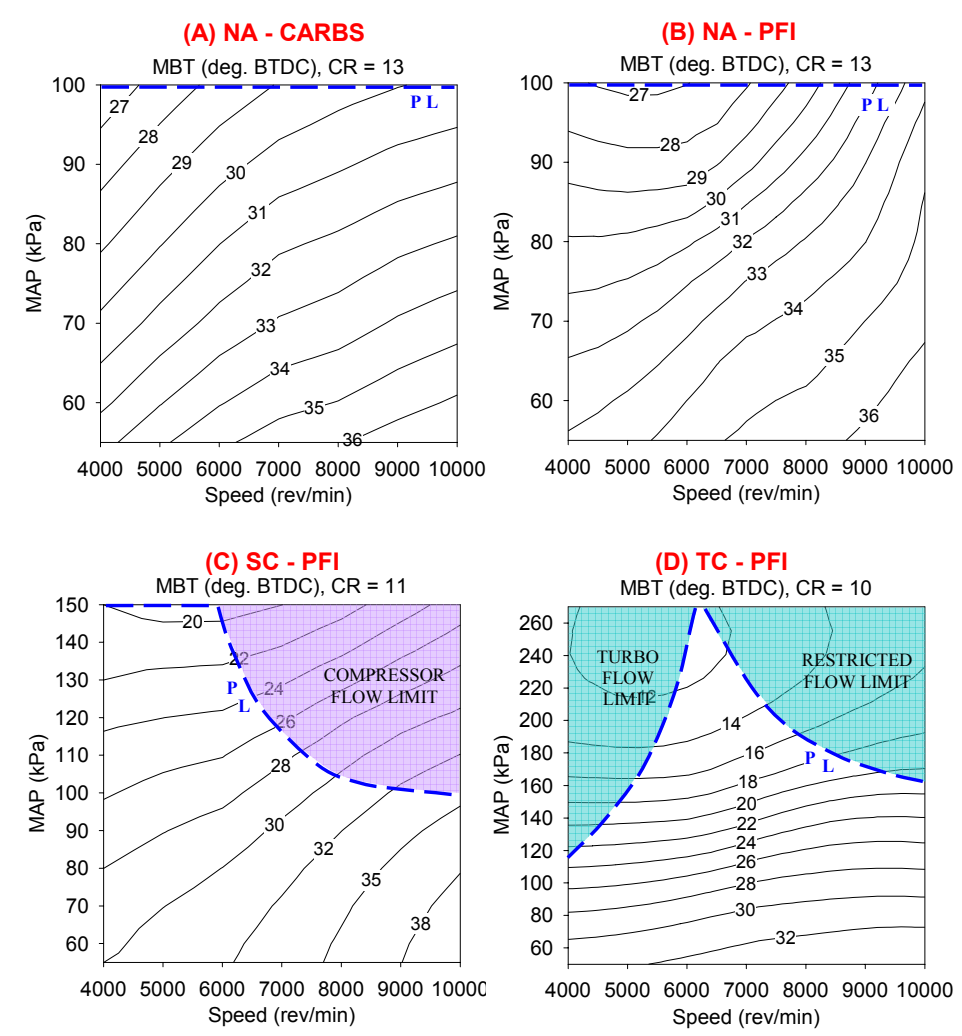

Figure 12: Spark timing trends at the test CR closest to optimal, varied MAP and speed conditions. Shaded areas indicate airflow limited regions. PL is the performance limit line defined at WOT.

\section{VOLUMETRIC EFFICIENCY ( $\left.\eta_{\text {VOL }}\right)$}

As can be seen from Figure 13, the $\eta_{\mathrm{NOL}}$ increases as a function of MAP for a given engine speed. For the boosted modes, the $\eta_{\mathrm{VO}}$ contour lines begin to diverge as the MAP is increased past atmospheric $(100 \mathrm{kPa})$. This is associated with the decreasing air charge density caused by work heating the air during compression, with no intake charge cooling (intercooling and/or evaporative) used during testing.

Trends suggest that for a given MAP above $80 \mathrm{kPa}$, air consumption rates are highly dependent on intake manifold resonant wave tuning. For the NA modes, the pressure waves in the inlet manifold begin to form, increasing in intensity to become most dominant at 100 $\mathrm{kPa}$ (WOT). This resonant wave, when correctly timed in the induction process, improves air consumption, cylinder trapping and reduces the exhaust residual gas content within the cylinder [24]. Resonant wave instantaneous pressures in the order of $180 \mathrm{kPa}$ absolute have previously been documented in NA systems [25]. In boosted applications, resonant tuning is generally less important as the engine airflow can be increased using the compressor, with the higher intake pressures naturally causing through scavenging during valve overlap to reduce the residual gas content. 
(A) NA - CARBS

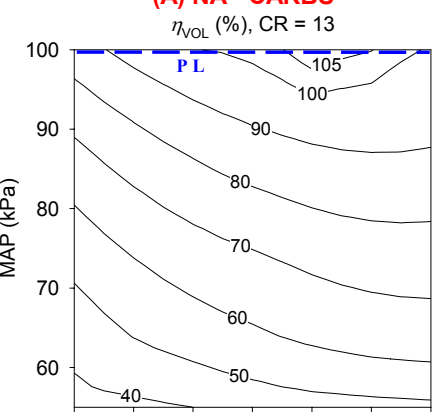

40005000600070008000900010000 Speed (rev/min)

(C) SC - PFI

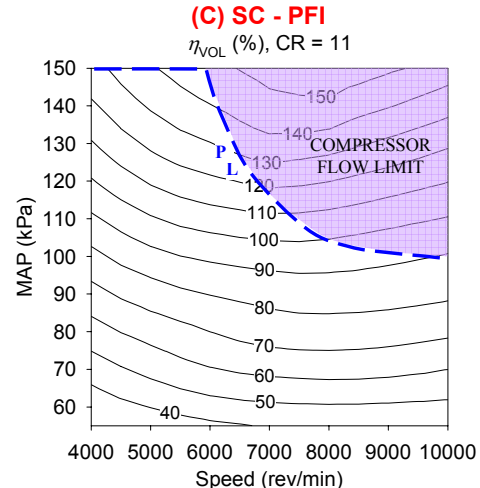

(B) NA - PFI

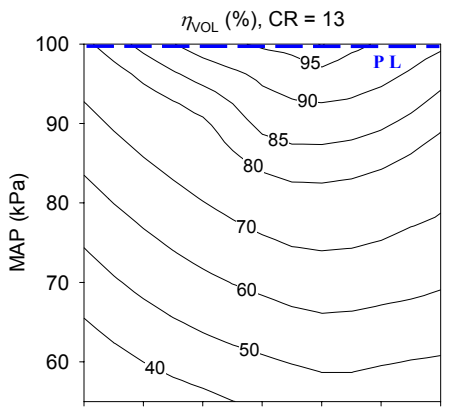

40005000600070008000900010000 Speed (rev/min)

(D) TC - PFI

$\eta_{\mathrm{VOL}}(\%), \mathrm{CR}=10$

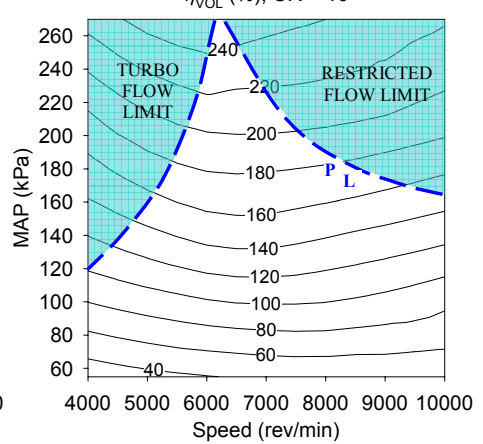

Figure 13: $\eta_{\mathrm{VOL}}$ trends at the test CR closest to optimal, varied MAP and speed conditions. Shaded areas indicate airflow limited regions. $\mathrm{PL}$ is the performance limit line defined at WOT.

\section{BRAKE SPECIFIC FUEL CONSUMPTION (BSFC) and THERMAL EFFICIENCY $\left(\eta_{\mathrm{TH}}\right)$}

Figure 14 displays $\mathrm{BSFC} / \eta_{\mathrm{TH}}$ contours with the corresponding lambda data for the varying modes. It must be noted that lambda variations existed between modes, making it difficult for direct comparisons, however trends can be analysed.

Peak $\eta_{\mathrm{TH}}$ for all modes occurred in the $80-90 \mathrm{kPa}$ MAP, $5000-6000 \mathrm{rev} / \mathrm{min}(10 \mathrm{~m} / \mathrm{s}$ mean piston speed) region as a result of high mechanical efficiency combined with fuel mixtures which were nearer to stoichiometric. However, further improvements were expected from intake charge boosting, particularly turbocharging $[2,3,4,5,6,7,8]$. These results did not eventuate, largely because of the excessive increases in fuel enrichment and spark retard needed to control knock with the rising MAP. However, if knock could be controlled via other methods previously defined, improvements in $\mathrm{BSFC} / \eta_{\mathrm{TH}}$ are expected. Consistently, across the speed range for all modes, BSFC/ $\eta_{\mathrm{TH}}$ results were poor at low MAP due to the high residual fraction, low mechanical efficiency and high pumping losses. At higher MAP near WOT, efficiency results were also poor as peak power was targeted in the NA modes and knock suppression in the boosted modes, thus necessitating the need for rich fuel mixtures.

(A) NA - CARBS
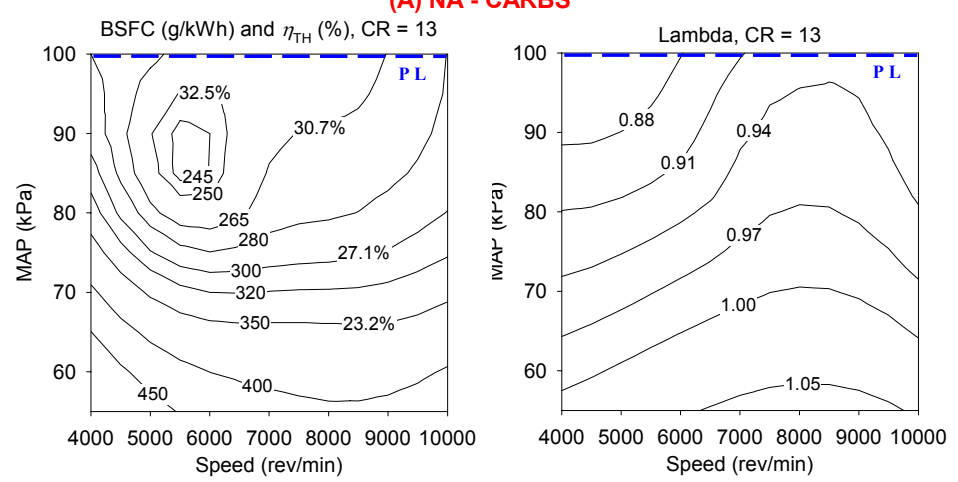

(B) NA - PFI

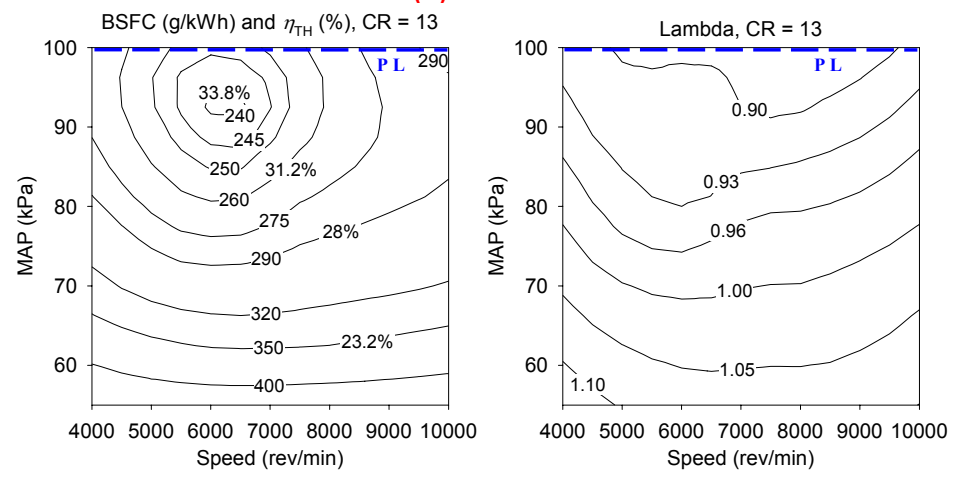

(C) SC - PFI

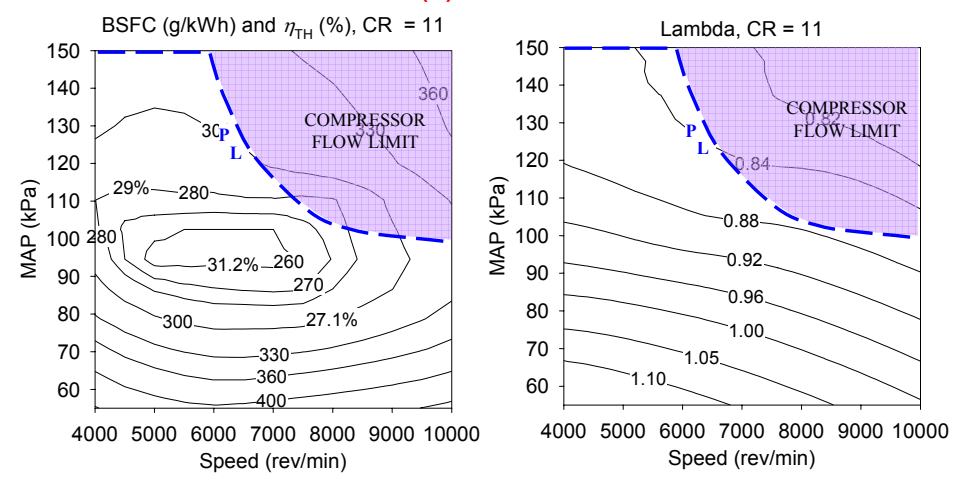

(D) TC - PFI
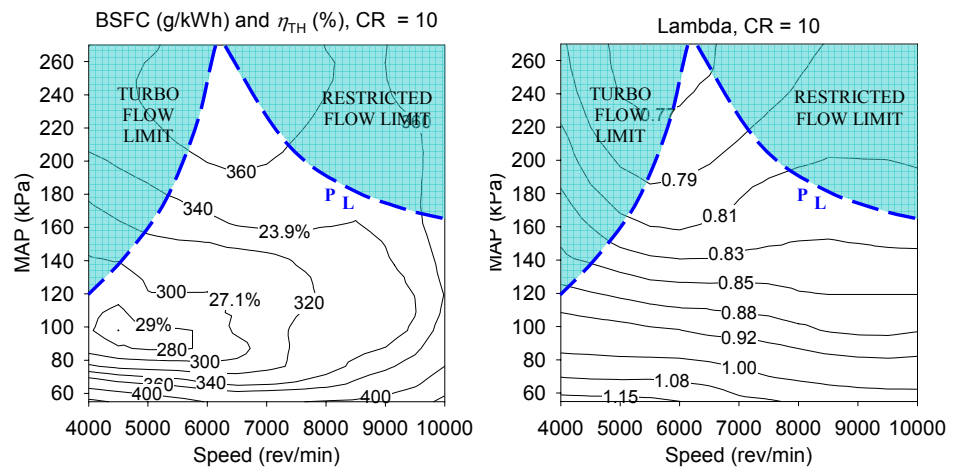

Figure 14: $\mathrm{BSFC} / \eta_{\mathrm{TH}}$ and corresponding Lambda at the test CR closest to optimal, varied MAP and speed conditions. Shaded areas indicate airflow limited regions. PL is the performance limit line defined at WOT. 


\section{MODE COMPARISONS AT THE PL (WOT)}

Comparisons are made at the WOT case at the test CR closest to optimum, to evaluate each mode's performance and efficiency. The WOT case as previously defined corresponds to the PL line, with MAP values for each mode varying, but clearly defined in Figure 15. In the TC mode, MAP decreases above 6000 $\mathrm{rev} / \mathrm{min}$ as the boost pressure ratio is reduced from 2.8 to maintain sonic flow conditions through the restricted inlet. The removal of the mandatory intake restriction would be expected to deliver sustained MAP values above this speed if the turbocharger surge limit could be avoided. The SC mode also shows a similar trait with decreasing MAP, however, this is due to the externally driven Roots blower being incapable of delivering the required airflow to maintain half an atmosphere of boost at the elevated speeds.

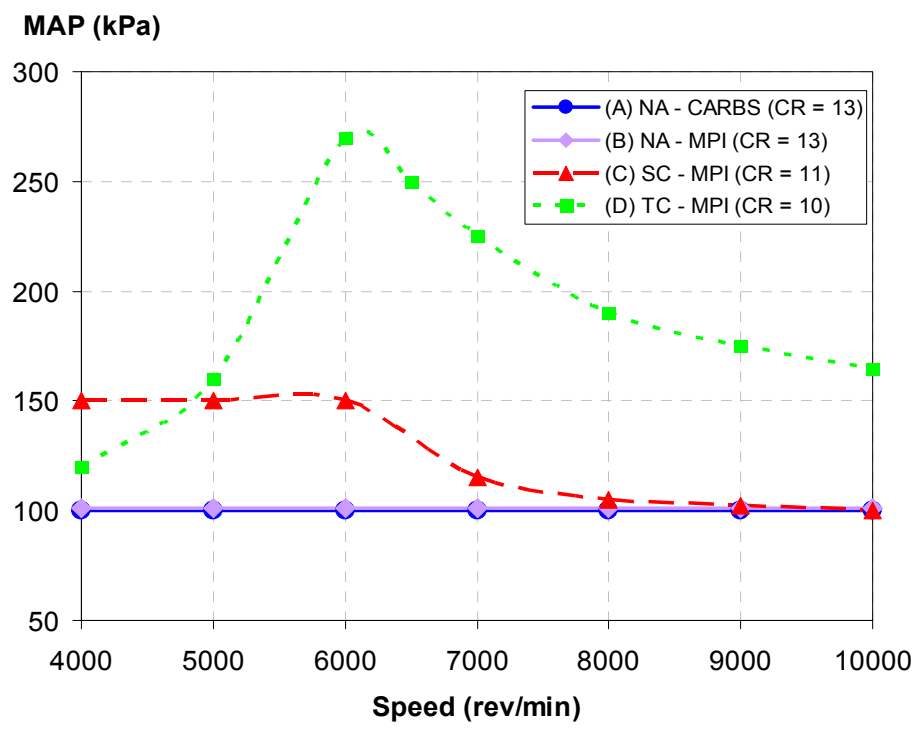

Figure 15: Maximum MAP values achieved at the PL (WOT) for all modes at the experimental test CR closest to optimal. In the TC mode, sonic flow conditions are evident above 6000 $\mathrm{rev} / \mathrm{min}$.

Performance characteristics are displayed in Figure 16, with BMEP, brake power and MBT compared for the varying modes. For NA operation, the BMEP and resultant brake power for the PFI system is reduced when compared to the carbureted system over all speeds, despite equal CRs. This is primarily due to airflow differences between both modes, as shown by the $\eta_{\text {VOL }}$ in Figure 17 (upper). This is associated with the PFI system being fitted with the $20 \mathrm{~mm}$ restrictor and corresponding plenum chamber. In NA operation, engine air consumption rates were not high enough to choke the restrictor, however, the intermittent pulsing attributed to the odd firing order limited instantaneous peak airflow through the nozzle, resulting in the plenum chamber being partially scavenged. To smooth out the large flow fluctuations through the restrictor, larger volumes downstream are needed, thus compromising transient response. This effect increases with engine speed, resulting in further reductions in performance at the elevated speeds.
BMEP (kPa)

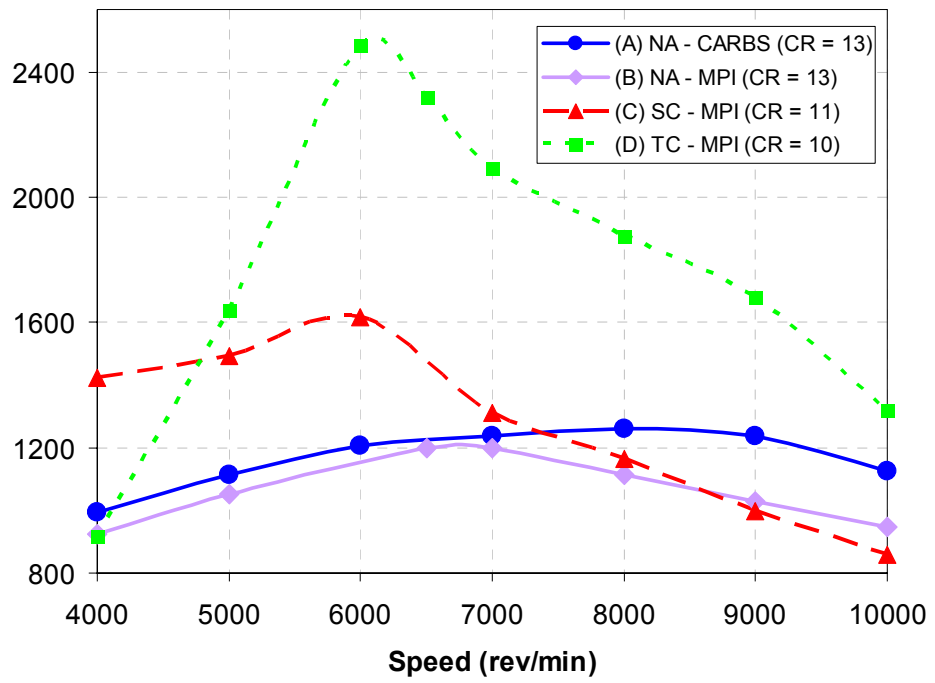

Brake Power (kW)

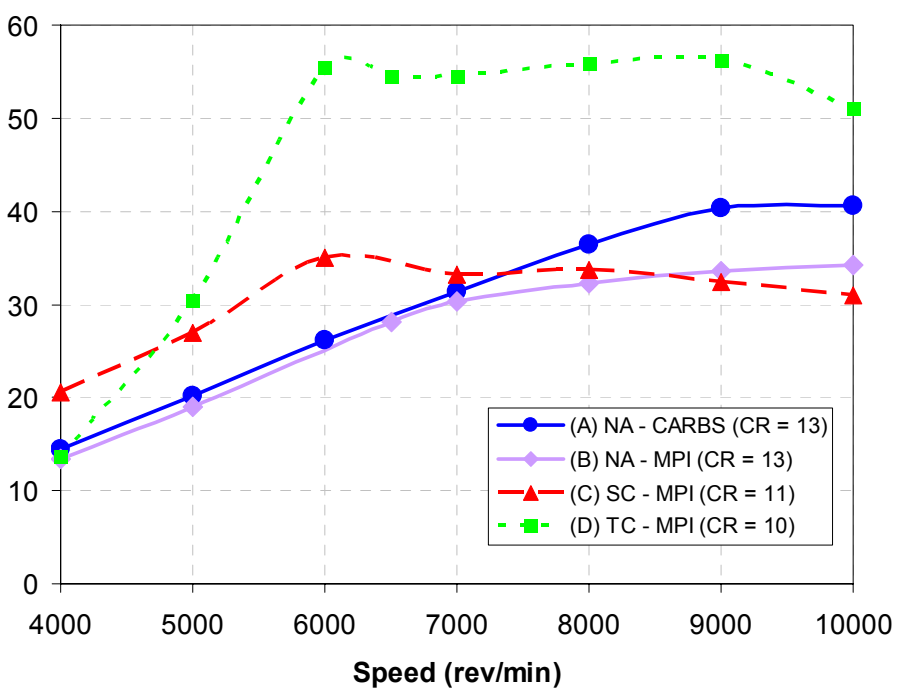

Spark Timing (deg. BTDC)

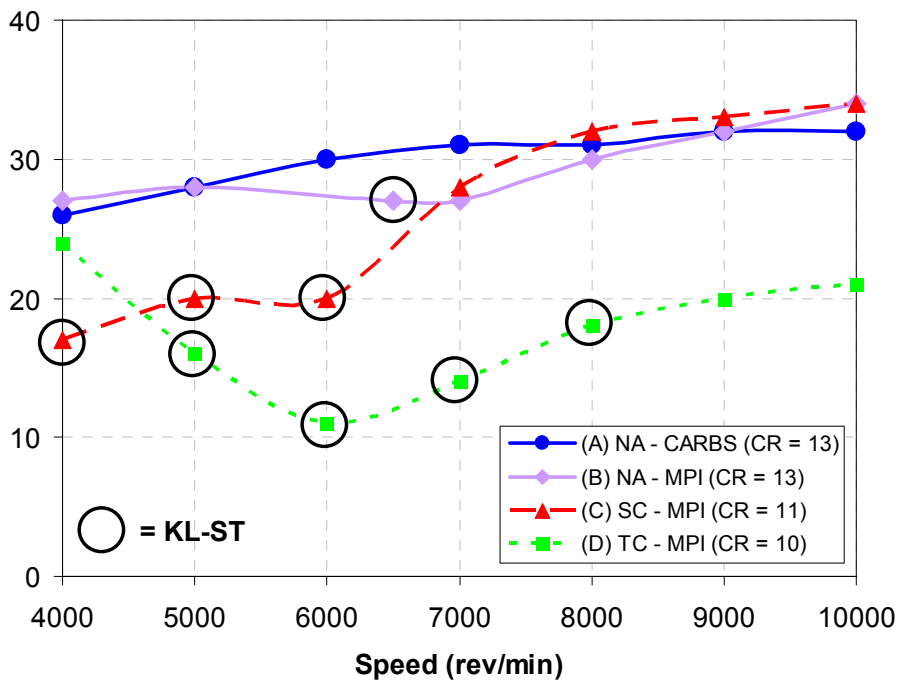

Figure 16: Performance comparisons at the PL (WOT) for all modes, (upper) BMEP, (middle) Brake Power, (lower) Spark Timing. 
The odd firing order effect also contributed to the $2^{\text {nd }}$ cylinder having reduced airflow due to the plenum being partially evacuated by the immediate previous induction. With the induction between the first and second cylinders spaced by $180^{\circ} \mathrm{CA}$, there was insufficient time for recovery, resulting in an uneven air distribution between cylinders. This resulted in cylinder variations in $\eta_{\text {NOL }}$ and trapped residual gas fraction, as confirmed by each cylinder's exhaust gas analysis. Thus, individual cylinder fueling requirements were needed to equalise air/fuel mixtures, with up to a $10 \%$ trim needed for the $2^{\text {nd }}$ cylinder at WOT conditions. This charge robbing effect could be minismised with improvements in intake manifold design. However, the plenum chamber geometry and volume had been optimized for TC operation using modeling aided by WAVE [14].

Figure 16 (upper) displays a comparison of BMEP, with a peak value of 25 bar recorded in the highly TC mode. This exceeds the highest specific output in recent evaluation of small cylinder TC engines, reported to be 22 bar from GM's 2.0-L TC Ecotec engine [1]. The WATTARD values have greater significance in that the GM value was achieved with intercooling, DI, dual scroll turbocharging, variable valve timing (VVT) and sodium cooled valves, which are all advantageous in increasing performance, reliability and reducing knock severity. The increased performance from the WATTARD engine is due to the reduced bore size, which promotes increases in engine speed and reduced end-gas volume around the periphery of the chamber. This allows CR and/or MAP values to be increased before exceeding the $\mathrm{DL}$.

Figure 16 (middle) demonstrates the engine's ability to deliver almost constant power over the 6000-10000 $\mathrm{rev} / \mathrm{min}$ speed range in the TC mode. At $6000 \mathrm{rev} / \mathrm{min}$ with a boost pressure just under two atmospheres, the engine's peak torque is 2.6 times that of the NA - PFI version. From this speed upward, the torque falls as the power is limited by sonic flow through the restriction.

Despite the cam timing and exhaust system being optimised for TC running, the relatively high BMEP of the NA modes indicates excellent port design and high mechanical efficiency, which produces higher BMEP values when compared to engines normally used in this Formula [11,12]. This was identified to be an important factor in obtaining the best possible torque before the turbocharger produces waste-gate limited boost [7].

The spark timing shown in Figure 16 (lower) highlights the knock limited areas (KL-ST), with spark retard used for control. The non-knock limited boosted areas display significant reductions in spark timing when compared to the NA modes due to charge density increases. This increased charge density significantly enhances the combustion process due to the increased flame speeds. This is highlighted at $10000 \mathrm{rev} / \mathrm{min}$, with the TC version requiring $10^{\circ}$ less spark advance to achieve MBT-ST at the elevated MAP.

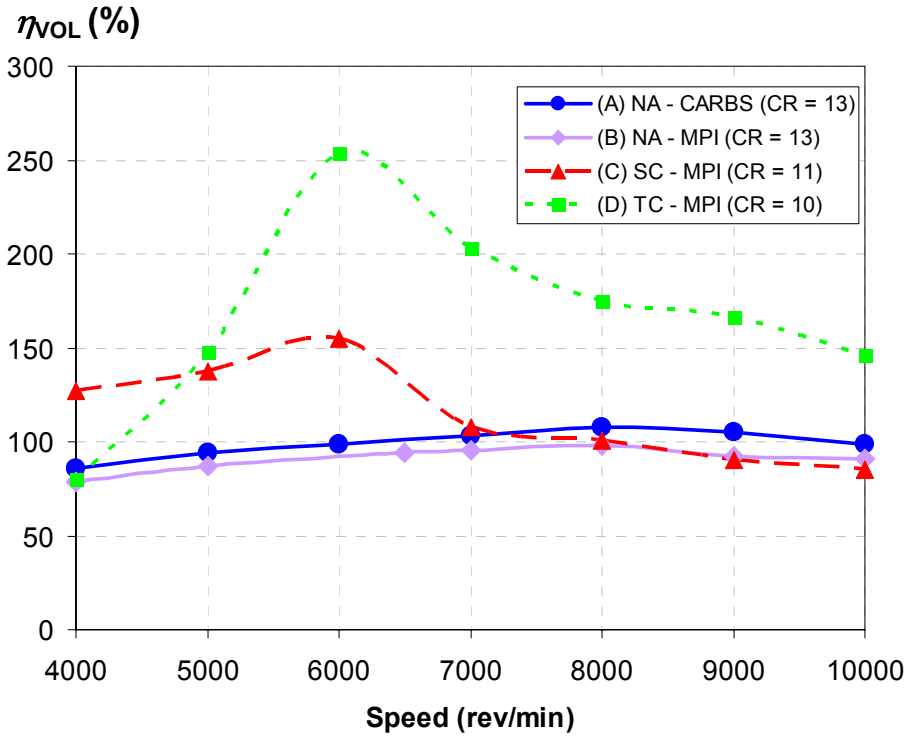

BSFC (g/kWh)

$\eta_{\mathrm{TH}}(\%)$

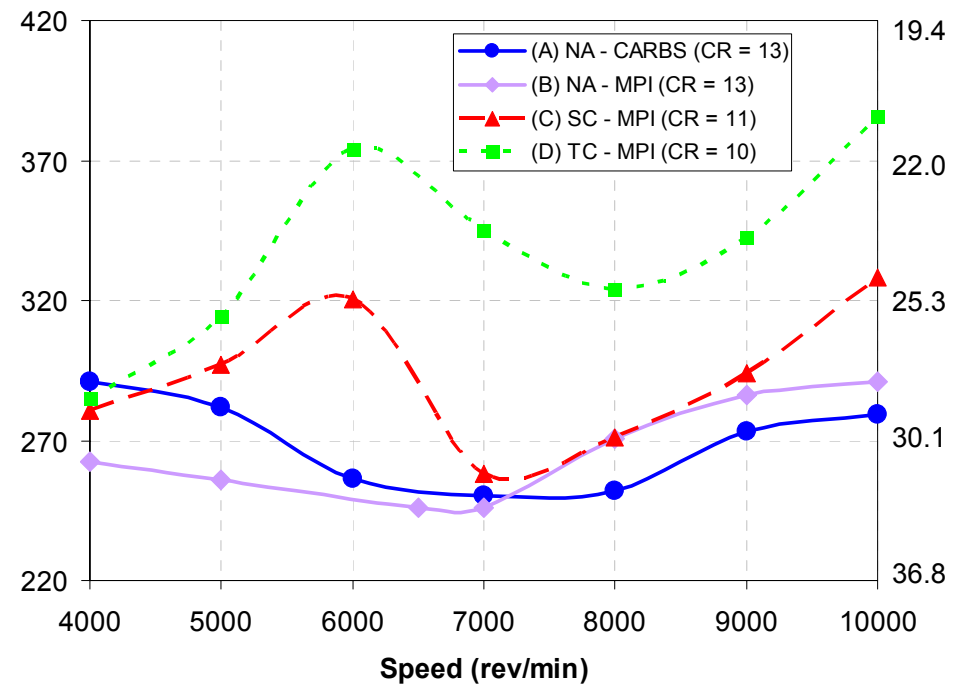

BSFC corr to $\lambda=1$ (g/kWh)

$\eta_{\mathrm{TH}}$ corr to $\lambda=1(\%)$

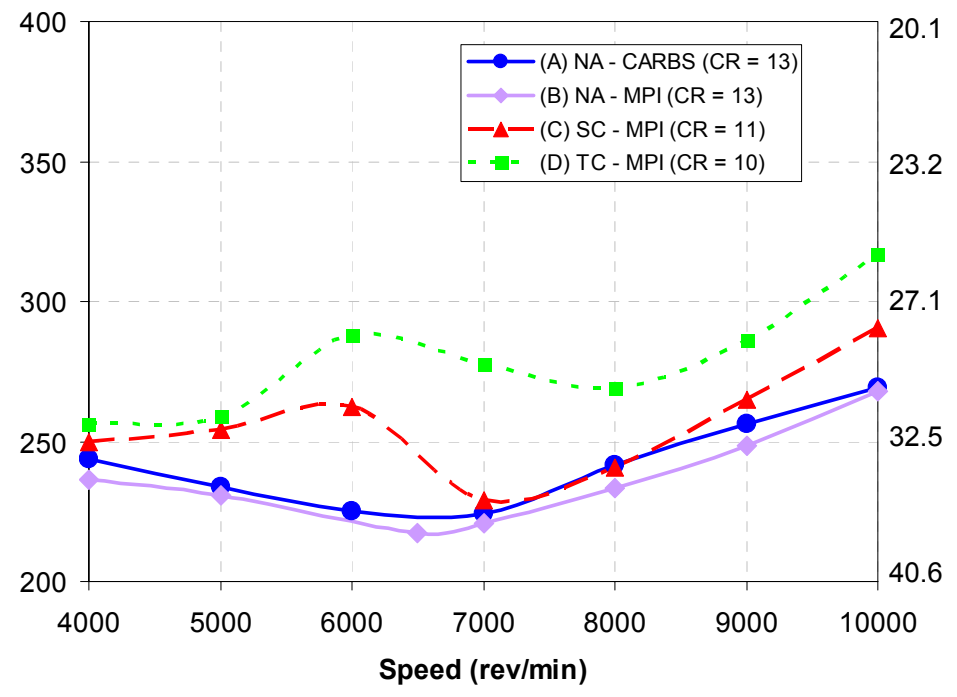

Figure 17: Efficiency comparisons at the PL (WOT) for all modes, (upper) $\eta_{\mathrm{VOL}}$, (middle) BSFC $/ \eta_{\mathrm{TH}}$, (lower) BSFC $/ \eta_{\mathrm{TH}}$ corrected to Lambda 1. 
A peak $\eta_{\mathrm{NOL}}$ of $250 \%$ was achieved in the TC mode as shown in Figure 17 (upper). The airflow reductions observed in the NA-PFI mode previously described are significantly reduced in the boosted modes, as the engine is force fed air via the compressor. This minimizes the pulsing effect caused by the piston motion during induction, with the compressor constantly inducing the maximum mass flow through the orifice. In the unrestricted carbureted mode, resonant wave tuning has allowed $\eta_{\text {NOL }}$ 's to exceed $100 \%$ between 7000 and $9500 \mathrm{rev} / \mathrm{min}$. A peak $\eta_{\text {VOL }}$ of $108 \%$ was also recorded at $8000 \mathrm{rev} / \mathrm{min}$.

Figure 17 (middle, lower) demonstrates the engine's fuel efficiency at the PL (WOT). Raw results are shown together with results corrected to stoichiometric conditions, to better evaluate effects due to the varying AFR. A best raw BSFC/ $\eta_{\text {TH }}$ value of $245 \mathrm{~g} / \mathrm{kWh}$ or $33 \%$ was achieved at WOT conditions for the NA-PFI mode, corresponding to the highest CR used in testing. When values are corrected to stoichiometric conditions, it is clear that the PFI system has advantages in fuel atomization and vapourisation over the carbureted system, resulting in improved mixing and thus improving $\mathrm{BSFC} / \eta_{\mathrm{TH}}$. However, the expected improvements in efficiency from turbocharging have not been realised. This is mainly due to the varying MAP, resulting in the $\mathrm{CR}$ being significantly reduced to avoid the $\mathrm{DL}$ at the highest pressure ratio. Consequently, this has compromised the efficiency at lower boosted operating conditions.

\section{CONCLUSIONS}

The performance and efficiency of a downsized Formula SAE engine running in a variety of NA and forced induction modes on 98-RON pump gasoline has been described, with the limiting factors compared. Modes are defined by variations in the induction system and associated engine modifications, namely compression ratio optimization, which was needed to avoid uncontrolled end-gas knock and maximize $\eta_{\text {NOL }}$. These modes included:
(A) NA with carburetion
(B) NA with PFI
(C) Mildly SC with PFI
(D) Highly TC with PFI

The test engine used in experiments was specifically designed and configured for the purpose, being a 430 $\mathrm{cm}^{3}$, twin cylinder in-line arrangement with double overhead camshafts and four valves per cylinder.

A peak value of 25 bar BMEP was achieved while running in the highly TC mode, believed to be the highest recorded value for small engines on pump gasoline [1]. This exceeds GM's highest specific output, recently reported to be 22 bar from their 2.0-L TC Ecotec engine [1]. The increased performance from the WATTARD engine is due to the reduced bore size, which promotes increases in engine speed and end-gas volume reductions around the periphery of the chamber. This allows CR and/or MAP values to be increased before exceeding the $\mathrm{DL}$.

Knock has been highlighted as being the single most important limiting factor in defining the performance for downsized boosted engines. Testing demonstrated that spark retard and/or fuel enrichment can be used as a method of knock control for up to 1-2 CR points depending on the knock severity. Testing also showed that knock severity is highest on the intake side in a pent roof combustion chamber. This is due to the knock onset location's dependence on the flame speed, which is severely reduced as the flame travels over the cooler surfaces of the intake valves.

Experimental results showed BSFC or $\eta_{\mathrm{TH}}$ values in the order of $240 \mathrm{~g} / \mathrm{kWh}$ or $34 \%$ could be achieved. Constant power could also be achieved over half the speed range in the highly TC mode due to the Formula SAE regulated intake restriction, which limited power. The engine was installed into successive MUR Motorsport vehicles in 2003 and 2004 and became the first prototype engine to successfully compete in the competition. The engine and vehicle package proved to be very competitive, finishing first in the fuel economy event at the 2004 Australasian competition.

Experimentation and competition results have proven that the performance of downsized engines can match that of their larger counterparts, with the aid of intake boosting. However, the extent to which swept volume can be reduced in any downsized application is combustion limited. If the combustion in high speed, small bore engines could be better understood or even enhanced to promote faster burning $[20,23,26]$, the severity of end-gas knock could be minimized. This would allow further increases in $\mathrm{CR}$ and/or MAP, resulting in increased performance and efficiency.

\section{ACKNOWLEDGMENTS}

The first author would like to thank fellow co-authors Steve Konidaris and Mohammad Ali Khan for the support given and the constant belief that we could successfully develop our own engine. The deep thought and discussion shared was invaluable in finding a solution to any problem faced. Focus was never lost on delivering a high performance reliable unit, even after many failures and continuous setbacks. Thanks are also due to co-author Professor Harry Watson, for his continual support of this project and his portrayal of Formula SAE as an invaluable training experience for undergraduates here at Melbourne.

The authors are also thankful for the patience, support and understanding of family and friends as days would go by where the team would not leave the thermodynamics lab. The team is also grateful, to all academic, postgraduate, and technical staff involved for their persistence, patience and support during the most trying times. Who said engine development was easy? 
To the generous sponsors that made the UniMelb 'WATTARD' engine possible, we offer our sincere thanks for supporting the excellent learning activity at the University of Melbourne.

$>$ ACL Bearing Company -

$>$ APEP Pistons -

$>$ Argo Engineering -

$>$ Bishop Innovation -

$>$ Bohler Uddeholm -

$>$ CadCore Pty Ltd -

$>$ Concentric Asia Pacific -

$>$ Cosway Motorcycles -

$>$ Davies Craig -

$>$ Electromold -

$>$ Farley Laserlab -

$>$ Garrett Honeywell -

$>$ Kawasaki Australia -

$>$ Magnesium Technologies -

$>$ MAME Centre for Manufacturing -

$>$ M\&W Ignitions -

$>$ Penrite Lubricants -

$>$ QMI Solutions -

$>$ Ricardo -

$>$ Robert Bosch -

$>$ Siemans VDO -

$>$ Southside Cylinder Heads -

$>$ University of Melbourne -

$>$ Wade Camshafts -

$>$ Whitehorse Industries -
NA

$P C$

$\mathrm{PL}$ performance limit

RON research octane number

SC supercharged

SI spark ignition

ST spark timing

TC turbocharged

VVT variable valve timing

WOT wide open throttle

$\eta_{\mathrm{TH}} \quad$ thermal efficiency

$\eta_{\text {NOL }} \quad$ volumetric efficiency

\section{REFERENCES}

1. Automotive Engineering International, 'Traveling the Long Road to Gasoline Direct Injection', SAE International, June. (2006)

2. LAKE, T., STOKES, J., MURPHY, R., OSBORNE, R. and SCHAMEL, A., 'Turbocharging Concepts for Downsized DI Gasoline Engines', SAE paper 200401-0036. (2004)

3. LECOINTE, B. and MONNIER, G., 'Downsizing a Gasoline Engine Using Turbocharging with Direct Injection', SAE paper 2003-01-0542. (2003)

4. PETITJEAN, D., BERNARDINI, L., MIDDLEMASS, C. and SHAHED, S.M., 'Advanced Gasoline Engine Turbocharging Technology for Fuel Economy Improvements', SAE paper 2004-01-0988. (2004)

\section{NOMENCLATURE}

ASTM American Society for Testing Materials

AFR air/fuel ratio

BMEP brake mean effective pressure

BSFC brake specific fuel consumption

CA crank angle

CAD computer aided design

CFR Cooperative Fuel Research

$\mathrm{CO}_{2}$ carbon dioxide

COG center of gravity

CR compression ratio

DI direct injection

DOHC double overhead camshafts

DL damage limit

EGR exhaust gas recirculation

EMS engine management system

EVC exhaust valve closed

EVO exhaust valve open

GM General Motors

HC hydrocarbon

HEGO heated exhaust gas oxygen

IVC inlet valve closed

IVO inlet vale open

KA knock amplitude

$\mathrm{KL} \quad$ knock limit

MAP manifold absolute pressure

MBT maximum brake torque

MUR Melbourne University Racing

PFI port fuel injection

5. CAIRNS, A., BLAXILL, H., IRLAM, A., Exhaust Gas Recirculation for Improved Part and Full Load Fuel Economy in a Turbocharged Gasoline Engine', SAE paper 2006-01-0047. (2006)

6. KLEEBERG, H., TOMAZIC, D., LANG, O., and HABERMANN, K., 'Future Potential and Development Methods for High Output Turbocharged Direct Injected Gasoline Engines', SAE paper 2006-01-0046. (2006)

7. ROSENKRANZ, H.G., WATSON, H.C., BRYCE, W. and LEWIS, A. 'Driveability fuel consumption and emissions of 1.3 litre turbocharged spark ignition engine developed as a replacement for a 2 litre normally aspirated engine.' Proc. I.Mech.E., C118/86:139-150 pp. (1986)

8. WATSON, H.C., MILKINS, E.E., ROBERTS, K. and BRYCE, W., 'Turbocharging for Fuel Efficiency, SAE paper 830014. (1983)

9. HEYWOOD, J., 'Internal Combustion Engine Fundamentals', ISBN 007028637X. (1988)

10. MILIKEN, W.F. and MILIKEN, D.L., 'Race Car Vehicle Dynamics', ISBN 1-56091-526-9. (2005)

11. ATTARD, W, 'Design, Performance and Analysis of a Downsized Highly Turbocharged $0.45 \mathrm{~L}$ Formula SAE Engine', Current Ph.D. Thesis, Mech. Eng. Dept., Univ. of Melbourne. (2006) 
12. ATTARD, W. and WATSON, H.C., 'Development of a 430cc Constant Power Engine for FSAE Competition', SAE paper 2006-01-0745. (2006)

13. ATTARD, W., WATSON, H.C. and KONIDARIS, S., 'Highly Turbocharging a Restricted, Odd Fire, Two Cylinder Small Engine - Design, Lubrication, Tuning and Control', SAE paper 06MSEC-38. (2006)

14. KARAGOUNIS, T. and STRAUS, 'Development of a 90 bhp Turbocharged Engine for use in Formula SAE-A', Undergraduate Thesis, Mech.Eng. Dept, Univ. of Melbourne. (2002)

15. ATTARD, W., WATSON, H.C. and KONIDARIS, S., 'Highly Turbocharging a Restricted Two Cylinder Small Engine - Turbocharger Development', SAE paper 07PFL-157. (2007)

16. ATTARD, W., WATSON, H.C. and STRYKER, P., 'Design and Development of a Gasketless Cylinder Head/Block Interface for an Open Deck, Multi Cylinder, Highly Turbocharged Small Engine', SAE paper 06SETC-104. (2006)

17. AS 4594.1-1999, 'Internal Combustion EnginesPerformance', Australian Standard. (1999)

18. ROTHE, M., HEIDENREICH, T., SPICHER, U. and SCHUBERT, A., 'Knock Behaviour of SI Engines: Thermodynamic Analysis of Knock Onset Locations and Knock Intensities', SAE paper 2006-01-0225. (2006)

19. OTOBE, Y., GOTO, O., MIYANO, H., KAWAMOTO, M., AOKI, A. and OGAWA, T., 'Honda Formula 1 Turbocharged V6 1.5 liter Engine', SAE paper 890877. (1989)

20. GERTY, M., and HEYWOOD, J. B., 'An Investigation of Gasoline Engine Knock Limited Performance and the Effects of Hydrogen Enhancement', SAE paper 2006-01-0228. (2006)

21. TAYLOR, C.F., 'The Internal Combustion Engine in Theory and Practice', Vol. 1 and 2, ISBN 0262700271. (1977)

22. CLOUGH, M.J., 'Precision Cooling of a Four Valve per Cylinder Engine', SAE paper 931123. (1993)

23. HAMORI, F., 'Exploring the Limits of Hydrogen Assisted Jet Ignition', Ph.D. Thesis, Mech.Eng. Dept, Univ. of Melbourne. (2006)

24. WATSON, H.C. and MILKINS, E.E., 'Cylinder Head Design', Modern engine developments Lecture 7246/1, University of Melbourne. (1972)

25. DAVIS, R.S. and PATTERSON, G.S., 'Cylinder Pressure Data Quality Checks and Procedures to Maximize Data Accuracy', SAE paper 2006-011346. (2006)

26. LUMSDEN, G. and WATSON, H.C., 'Optimum Control of a S.I Engine with a $\lambda=5$ Capability', SAE paper 950412. (1995)

\section{CONTACT}

Prof. Harry Watson

Head Thermofluids Group

Department of Mechanical Engineering University of Melbourne

Victoria, Australia, 3010

Email: harrycw@unimelb.edu.au

William Attard

Thermofluids Group

Department of Mechanical Engineering

University of Melbourne,

Victoria, Australia, 3010

Email: william_attard@hotmail.com 
WATTARD: 12: FUEL / INDUCTION SYSTEM A (NA - CARBS) (EXPLODED VIEW)
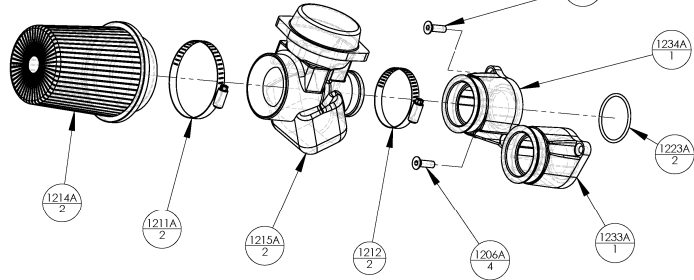

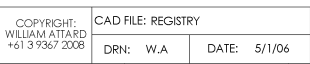
15. $\begin{gathered}\text { Department of } \\ \text { Mechnincal and } \\ \text { Manutacturing Engineerition }\end{gathered}$ \begin{tabular}{|c|c|c|}
\hline WATARD & SHEET & A4 \\
\hline
\end{tabular} (A) NA - CARBS
WATTARD: 12: FUEL / INDUCTION SYSTEM B (NA - EFI)

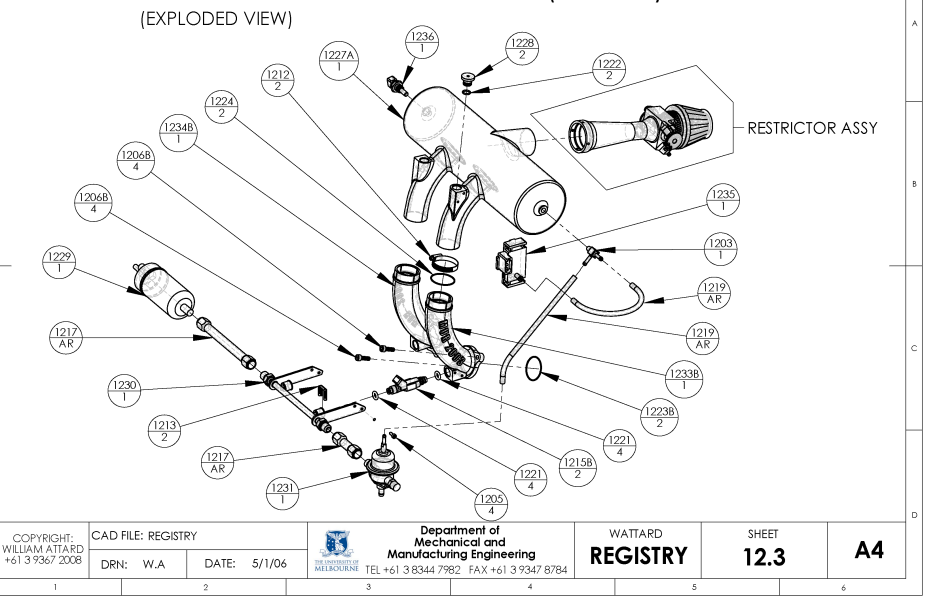

(B) NA - PFI and (C) SC - PFI

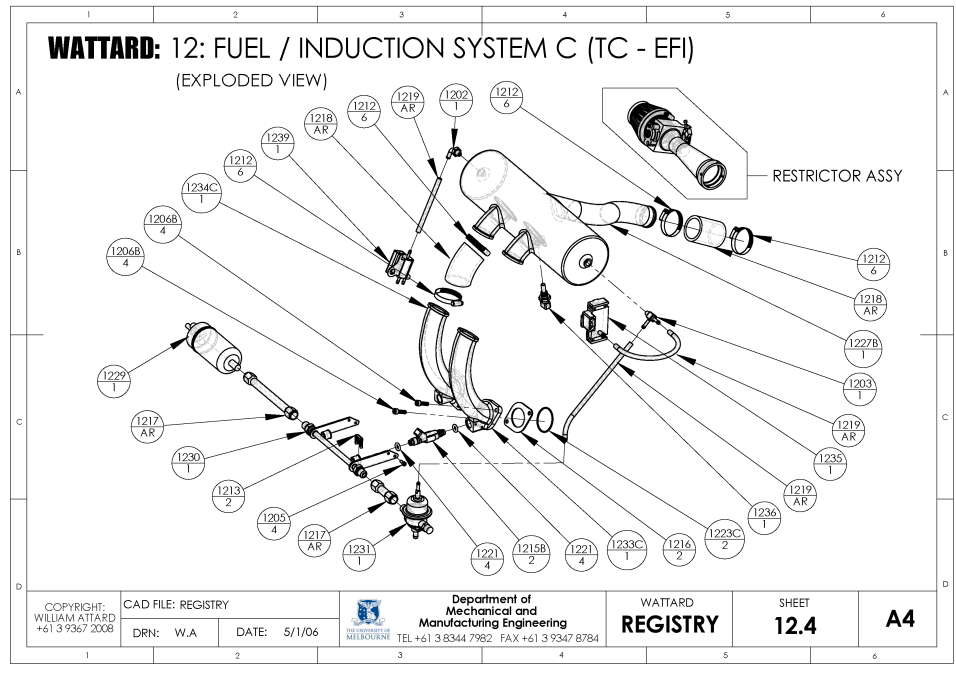

(D) TC - PFI

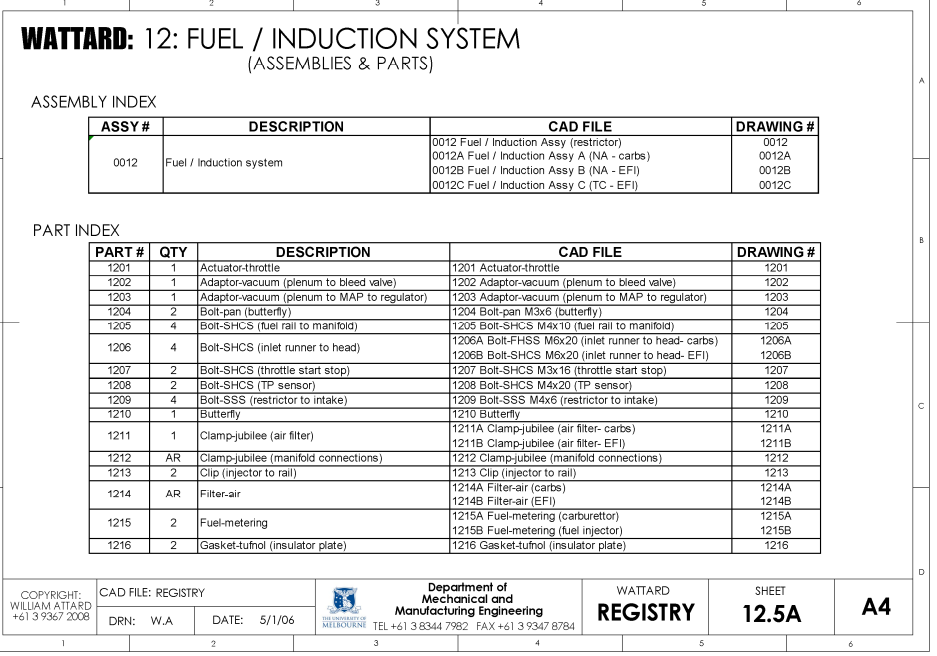

WATTARD: 12: FUEL / INDUCTION SYSTEM

PART INDEX

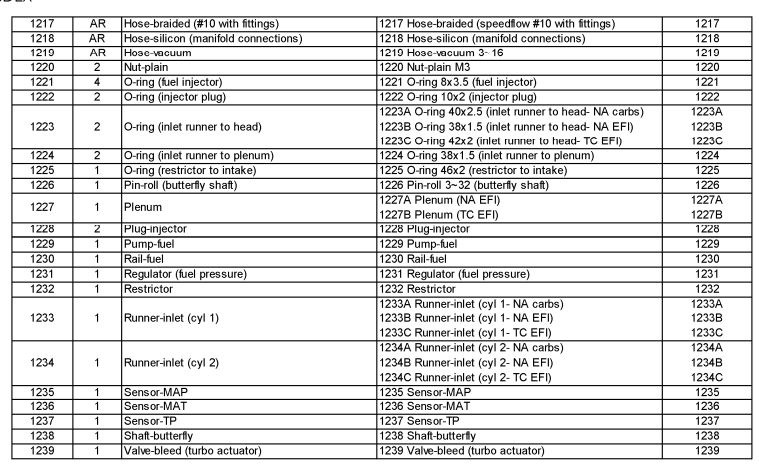

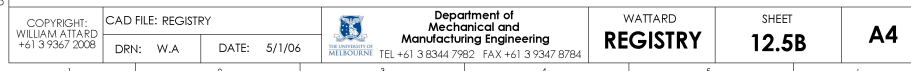


APPENDIX B: VARYING EXHAUST SYSTEMS

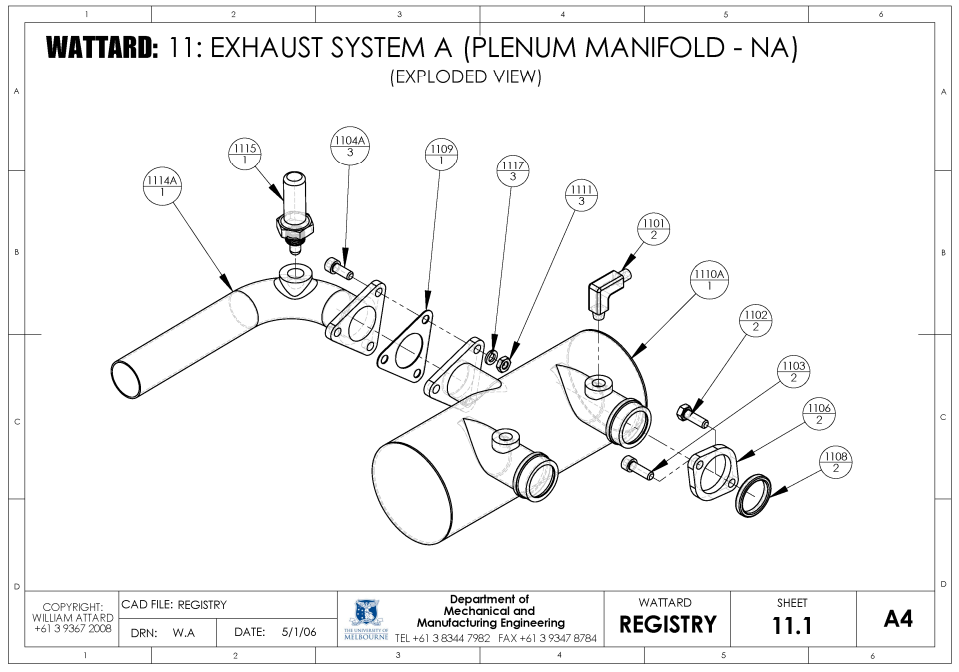

(A) NA - CARBS

(B) NA - PFI

(C) SC - PFI

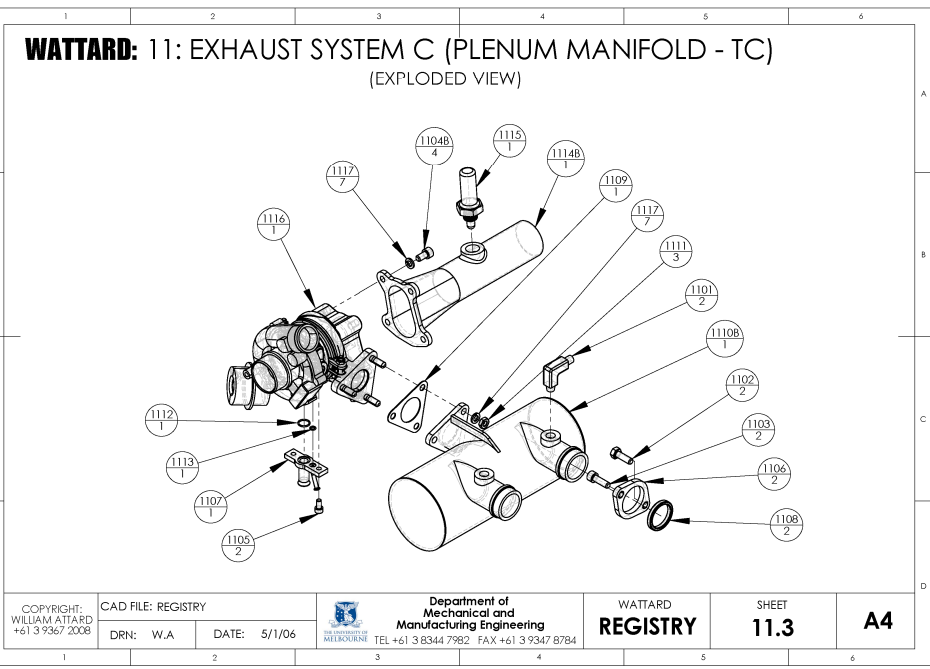

(D) TC - PFI

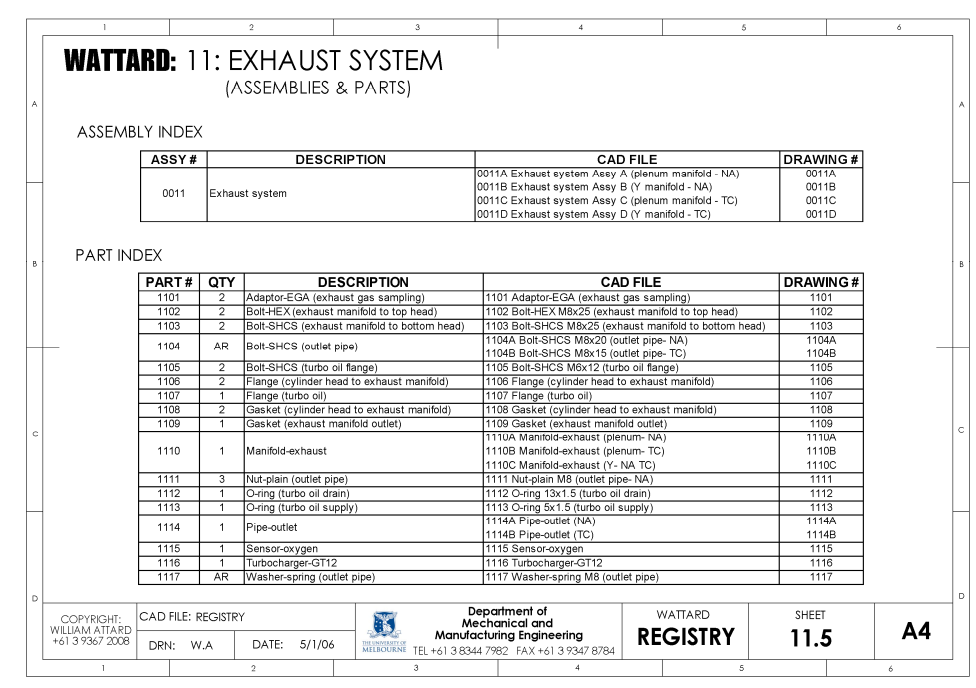

COMPONENT INDEX 


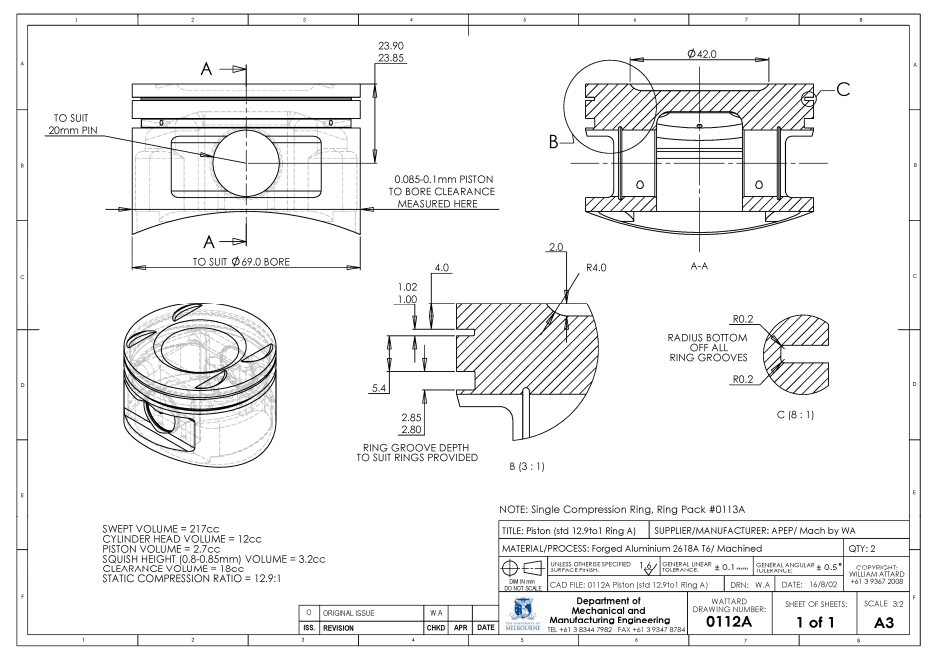

13:1 CR

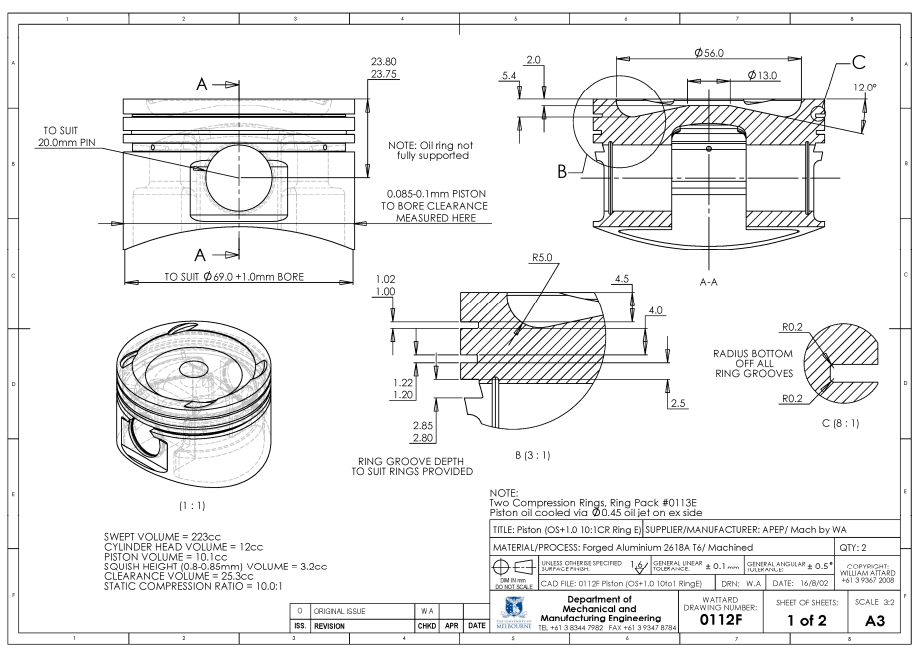

10:1 CR

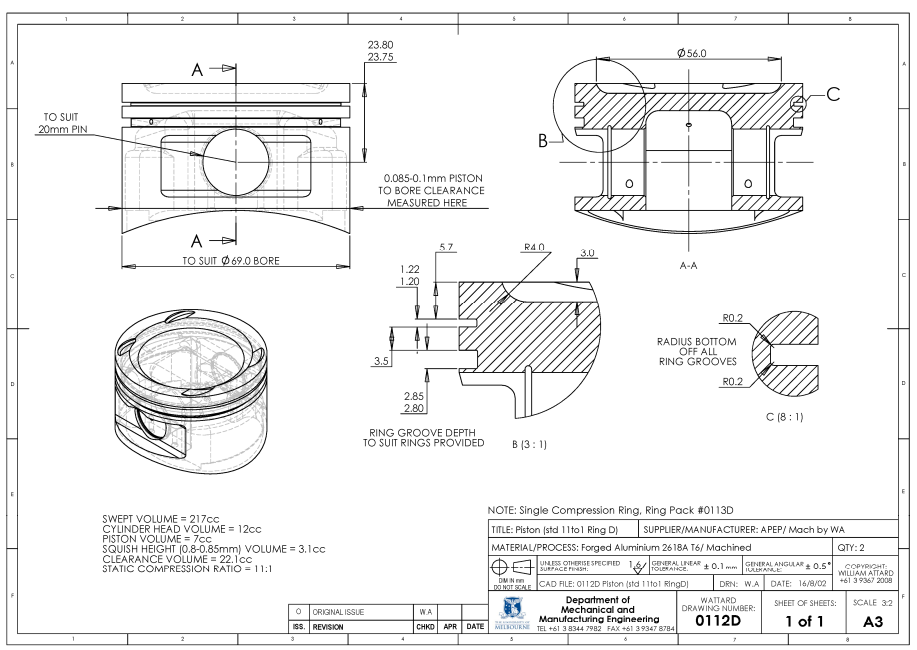

11:1 CR

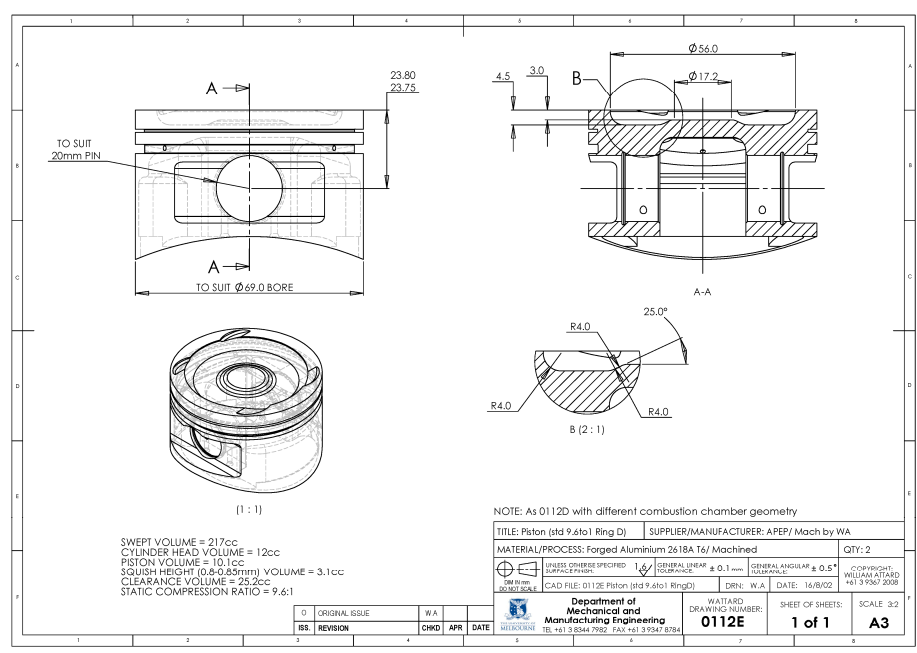

9.6:1 CR 


\section{University Library}

\section{- M I I N E R VA \\ A gateway to Melbourne's research publications}

Minerva Access is the Institutional Repository of The University of Melbourne

Author/s:

Attard, William;Watson, Harry;Konidaris, Steven;Khan, Mohammad

Title:

Comparing the performance and limitations of a downsized formula SAE engine in normally aspirated, supercharged and turbocharged modes

Date:

2006

Citation:

Attard, W., Watson, H., Konidaris, S., \& Khan, M. (2006). Comparing the performance and limitations of a downsized formula SAE engine in normally aspirated, supercharged and turbocharged modes. In, Proceedings, SAE International Small Engine Technology Conference, San Antonio, Texas, USA.

Publication Status:

Published

Persistent Link:

http://hdl.handle.net/11343/34450 